\title{
Milling Force Model for Aviation Aluminum Alloy: Academic Insight and Perspective Analysis
}

\author{
Zhenjing Duan ${ }^{1}$, Changhe $\mathrm{Li}^{1 *}$, Wenfeng Ding ${ }^{2}$, Yanbin Zhang ${ }^{1}$, Min Yang ${ }^{1}$, Teng Gao ${ }^{1}$, Huajun Cao ${ }^{3 *}$, \\ Xuefeng X ${ }^{4}$, Dazhong Wang ${ }^{5}$, Cong Mao ${ }^{6}$, Hao Nan Li ${ }^{7}$, Gupta Munish Kumar ${ }^{8}$, Zafar Said ${ }^{9}$, Sujan Debnath ${ }^{10}$, \\ Muhammad Jamil ${ }^{2}$ and Hafiz Muhammad $\mathrm{Ali}^{11}$
}

\begin{abstract}
Aluminum alloy is the main structural material of aircraft, launch vehicle, spaceship, and space station and is processed by milling. However, tool wear and vibration are the bottlenecks in the milling process of aviation aluminum alloy. The machining accuracy and surface quality of aluminum alloy milling depend on the cutting parameters, material mechanical properties, machine tools, and other parameters. In particular, milling force is the crucial factor to determine material removal and workpiece surface integrity. However, establishing the prediction model of milling force is important and difficult because milling force is the result of multiparameter coupling of process system. The research progress of cutting force model is reviewed from three modeling methods: empirical model, finite element simulation, and instantaneous milling force model. The problems of cutting force modeling are also determined. In view of these problems, the future work direction is proposed in the following four aspects: (1) high-speed milling is adopted for the thin-walled structure of large aviation with large cutting depth, which easily produces high residual stress. The residual stress should be analyzed under this particular condition. (2) Multiple factors (e.g., eccentric swing milling parameters, lubrication conditions, tools, tool and workpiece deformation, and size effect) should be considered comprehensively when modeling instantaneous milling forces, especially for micro milling and complex surface machining. (3) The database of milling force model, including the corresponding workpiece materials, working condition, cutting tools (geometric figures and coatings), and other parameters, should be established. (4) The effect of chatter on the prediction accuracy of milling force cannot be ignored in thin-walled workpiece milling. (5) The cutting force of aviation aluminum alloy milling under the condition of minimum quantity lubrication (mql) and nanofluid mql should be predicted.
\end{abstract}

Keywords: Milling, Aluminum alloy, Force model, Empirical model, Finite element model, Instantaneous milling force model

\section{Introduction}

Aviation aluminum alloy has high specific strength, low density, good thermal conductivity, corrosion

\footnotetext{
*Correspondence: sy_lichanghe@163.com; hjcao@cqu.edu.cn

${ }^{1}$ School of Mechanical and Automotive Engineering, Qingdao University

of Technology, Qingdao 266520, China

3 State Key Laboratory Mechanical Transmiss, Chongqing University,

Chongqing 400044, China

Full list of author information is available at the end of the article
}

resistance, and other properties, which make it widely used in aerospace manufacturing, automobile, and other industries [1]. In the aviation manufacturing industry, the integrated design is adopted to improve flight maneuverability, load, and ability of long-distance voyage and many skeleton parts, especially the main load-bearing structural parts [2,3]. At present, the civil airliners in use, such as the new Boeing 787 and Airbus A380, are dominated by aluminum alloy 
$[4,5]$. Moreover, the structural parts of the front fuselage, middle fuselage, middle fuselage, nose, and wings of the C919 are nearly all made of aluminum. Analyzing the aircraft types of major international civil aircraft manufacturers indicates that ultra-high-strength aluminum alloy still occupies an important position as the structural material of aircraft [6]. Ultra-highstrength aluminum alloy has a broad market application prospect in the aviation field as observed in the overall situation of developing civil large passenger aircraft in China [7].

Complex cavities, ribs, and platforms are often formed on the structural parts during the strength design to reduce the weight in the design process because of the large size, thin workpiece, and low relative stiffness of aeronautical structural parts. The aircraft structure easily deforms in the process of machining due to its large size and thin structure [8]. CNC milling method is mainly used, such as aircraft engine compressor wheel, inducer, impeller, and stressed structural members (e.g., girder stringer, bulkhead, integral panel, wing rib, landing gear, and aircraft skin frame) because of the complex structure of aircraft [9-12]. However, low cutting efficiency, easy deformation, and surface integrity of structural parts are the main problems that restrict the processing of aluminum alloy structural parts [13].

In the process of milling, milling parameters mainly include milling depth, speed, and feed rate [14-16]. In the selection of milling parameters, attention should be paid to the matching between workpiece and tool materials to maximize the machining characteristics of aircraft structural parts $[17,18]$. High-speed milling adopts the processing mode of high speed, high feed, and low cutting quantity. The milling force of the cutting tool is greatly reduced under the mode of high milling speed, and this condition effectively reduces the deformation error caused by the milling force. Therefore, high-speed milling processing can achieve superior effect in the processing of thin-walled parts of aviation aluminum alloy and parts with poor rigidity fruit [19]. Nowadays, the commonly used cutting schemes in high-speed milling are high cutting speed, medium feed rate, and small cutting depth. However, the setting of parameters in highspeed milling needs to be comprehensively considered from various aspects of workpiece, cutter, and equipment to ensure the machining quality and accuracy of aircraft structural parts to the maximum extent [20]. The angle of tool will also greatly affect the machining effect of the tool. The rake angle will considerably affect the service life of the tool. The rake angle of the tool in rough machining can be appropriately reduced to improve the service life of the tool, while the rake angle of the tool should be appropriately increased in the finishing process [21-23].

Radial and axial cutting depth parameters are important. In the process of aircraft structural part processing, choosing smaller axial cutting depth and larger radial cutting depth is beneficial after considering the processing parameters of aircraft structural parts from the aspects of milling force and residual stress in high-speed milling. Jiang et al. [24] established a milling force model and analyzed the influence of cutter geometry parameters (helical and front angle) and milling parameters (axial cutting depth, radial cutting depth, and feed per tooth) on milling force. The cutter in the milling mode of aircraft structural parts should be milling in the way of down milling, and the cutter should be cut slowly to reduce its radial force on the aircraft structural parts. Layered cutting, small cutting depth, and medium feed processing can be adopted when milling the end face of aircraft structural parts. Cycloid cutting method is needed for the corner part of the cavity of aircraft structural parts when machining the internal cavity of aircraft structural parts. This way avoids the deformation of workpiece caused by the increase in milling force in the machining process of aircraft structural parts and ensures their processing quality. Cooling lubrication methods in milling, such as pouring, dry, low-temperature cooling, minimum quantity lubrication (mql), nanofluid mql (nmql), and cryogenic mql, can also affect tool wear and surface integrity of structural parts [25-31].

The milling force directly affects the deformation and surface integrity of workpiece, and the milling force is the result of the coupling of multiparameters, such as milling depth, speed, feed rate, tool parameters, milling method, and cooling lubrication mode [32]. Therefore, the active prediction of milling force plays an important role in preventing machining deformation and improving the surface integrity and machining efficiency.

Scholars are currently conducting in-depth research on milling force modeling. Three milling force models are introduced in literature [33-35]. One is the empirical model, that is, the milling force is fitted into the function of cutting speed, feed per tooth, and axial and radial cutting depth depending on metal cutting theory. This model requires fitting of a large number of experimental data. The second is the finite element model. This model needs to be combined with the simulation software, which can be used for the finite element simulation of milling force and has a certain guiding role in the prediction of milling force. However, the prediction accuracy needs to be strengthened due to the deviation between the simulation and actual milling processes. The third is analytical model. The most common one is the model describing the instantaneous milling force. The model 
has the advantages of clear steps, high accuracy, and relatively simple program implementation process.

\subsection{Empirical Model}

The empirical model of milling force represents the milling force as a function of milling parameters, and the coefficients of the function are obtained through several milling experiments. Kwang et al. [36] established a milling force model by means of several experiments and statistical principles. They also analyzed the influence of spindle speed, feed per tooth, and radial and axial cutting depth on milling force. Yuan et al. [37] researched a quadratic model of predicting milling force using the response surface methodology. Shao et al. [38] conducted aluminum alloy milling experiment by using multi-factor orthogonal test method. They also established the empirical model of milling force of cemented carbide end mill.

\subsection{Finite Element Model}

The finite element method is commonly used research method in numerical simulation technology. This method can reproduce all kinds of physical phenomena in the machining process according to the actual processing conditions compared with other methods. M. R. Lajczok of North Carolina State University applied the finite element method in 1980 to study the main problems in the cutting process and preliminarily analyzed the cutting process. In recent years, the research on finite element simulation of metal cutting has become comprehensive at home and abroad and obtained achievements [39]. These models include orthogonal model, oblique angle model, 2D simulation, and 3D simulation, which are used to analyze the chip formation process, tool wear and geometric parameter optimization, and distribution of machining stress and temperature fields [40-43]. Saffar et al. [44] used the solid model of milling cutter to simulate the milling force and tool deformation, and the simulation results agree well with the theoretical calculation and experimental results. Gonzalo et al. [45] used the solid model of a double tooth cutter to conduct finite element analysis on the milling process for obtaining the milling force.

\subsection{Instantaneous Milling Force Model}

The geometry of the cutting edge of a milling cutter is generally complex space helix. As a result, the cutting state of each point on the cutting edge differs. The analytical modeling of milling force has two forms of tool geometry model: integral and differential separation. Abrari, Engin, Mann, and Bhattacharyya [46-49] established the milling force model and gave the integral form of instantaneous cutting thickness and other related parameters based on the integral form of milling cutter.
Most current studies use the differential discrete form to establish the milling force model [45,50-52]. The cutting edge is divided into several micro cutting edge units along the axis, which are called micro element cutting edge or cutting micro element. The force acting on the micro element cutting edge is called micro element cutting force. Each micro element is in the oblique cutting state, and the total milling force is the vector sum of the micro element cutting force. The milling force model established by this method mainly includes three parts: micro element cutting force, cutting force coefficient, and instantaneous cutting thickness models $[47,53]$.

For a long time, scholars have made efforts to predict metal cutting process. Machine tool manufacturers and production workshops need to estimate the cutting force in advance. Cutting force is an indispensable basis for calculating cutting power, designing, and using machine tools, tools, fixtures, and process systems. The prediction and measurement of milling force play an active role in selecting cutting parameters and geometric parameters of cutting tools, improving cutting productivity, and reducing production costs. The increasing number of CNC machine and the continuous emergence of difficult-to-machine and special materials have made cutting tool reliability, chip, and chip control increasingly important issues. Thus, we need to start from the various physical natures of milling force to accurately clarify the size of cutting force and its influence law. In this study, the research status of aeronautical aluminum alloy conventional milling, micro milling, thin-walled milling, and surface milling mechanical models are analyzed. Some unsolved problems still exist in the research of aeronautical aluminum alloy milling force model. Thus, the development trend of mechanical model research should be determined. This study proposes four research directions of milling force: (1) high-speed milling is adopted for the thin-walled structure of large aviation with large cutting depth, which easily produces high residual stress on the workpiece surface. Milling force is an important affecting factor of the distribution of residual stress in milling process. The residual stress should be analyzed under this particular condition. (2) Most researchers have mainly focused on one or two factors in establishing the instantaneous milling force model, and milling force is the result of multiparameter coupling, especially for micro milling and complex surface machining. The modeling of milling force should comprehensively consider multiple factors (e.g., milling parameters, lubrication conditions, tool eccentric runout, tool and workpiece deformation, and size effect). (3) Different numerical, analytical, and experimental methods have been applied. However, the database needs further development to include new workpiece materials, tools (geometries and 
coatings), working condition, and uncertainty quantification. This way can increase its utility. (4) The stiffness of thin-walled parts is very low. Thus, workpiece chatter easily occurs in the final finishing process. This condition is one of the affecting factors of the machining quality of thin-walled workpiece. However, the chatter of cutting tool and workpiece in the process of machining has been ignored in the current research to simplify the milling force model, which affects the accuracy of milling force to a certain extent. (5) mql and nmql are resource-saving and environment-friendly cooling lubrication methods, which are widely used in milling. However, most force models are established under dry or flood lubrication conditions and few are under mql. Therefore, the prediction of milling force under mql and nmql should be further analyzed.

In conclusion, not only the latest development of aeronautical aluminum alloy milling force model is reviewed but also the related research is comprehensively analyzed. On the basis of summarizing the existing problems, the development trend of milling force model research on aviation aluminum alloy is predicted. The mechanical model of aviation aluminum alloy is mainly divided into three aspects: empirical, finite element, and instantaneous milling force models. Thus, this study reviews the three aspects. Figure 1 shows the structure of the review paper.

\section{Influence of Milling Force}

The rapid development of aerospace, medical equipment, and automobile manufacturing industries has increased the application demand of aviation aluminum alloy materials [54]. Milling is an indispensable part in the processing of hard machining materials, in which the milling force is always the focus of research [55]. The variation law of milling force is the root of all other physical problems, and it directly affects the vibration, deformation, cutting heat, and surface quality during milling, as shown in Figure 2. The research of milling force has attracted great attention of scholars. The establishment of systematic prediction model of milling force to optimize process parameters, reduce tool wear, optimize tool life, and improve energy efficiency and surface machining quality has become the focus of research [2].

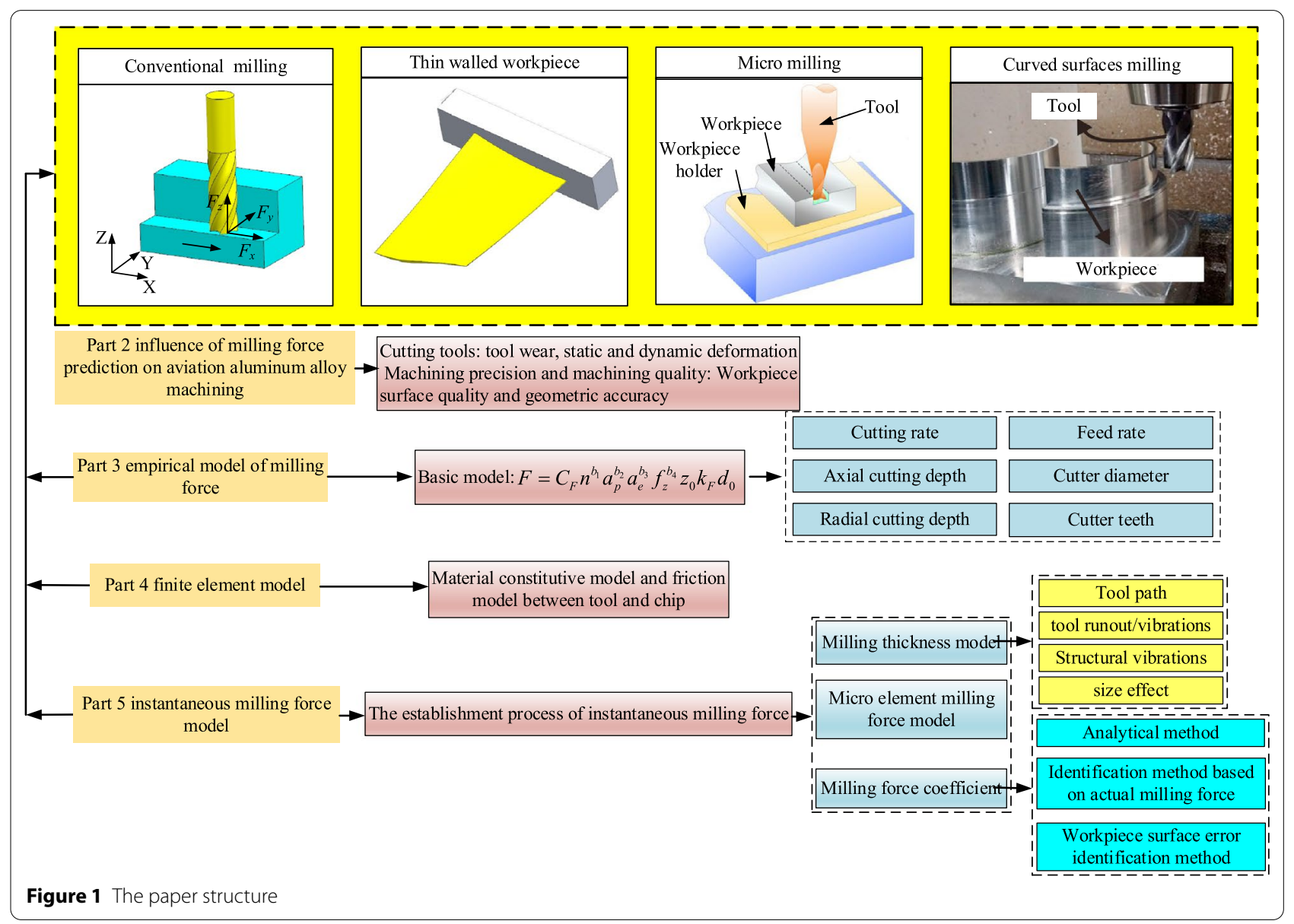




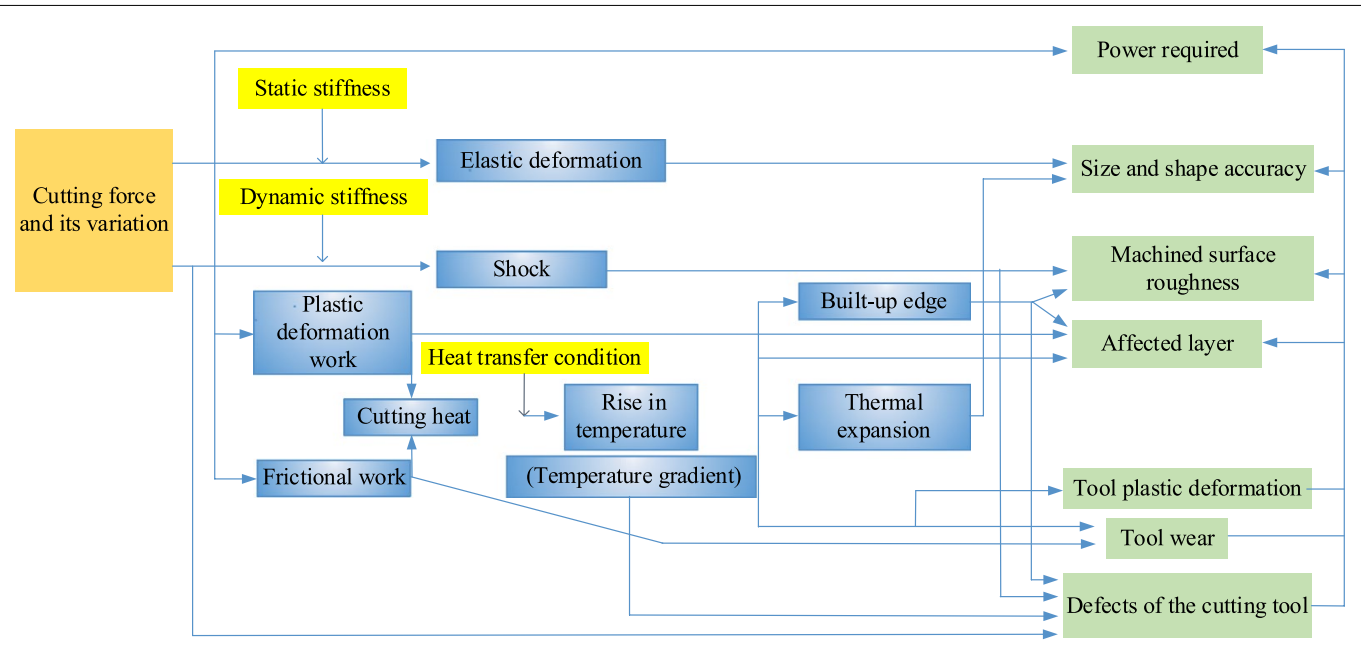

Figure 2 Effect of milling force

\subsection{Influence on Milling Tools}

Milling is common in the aviation industry. Complex end mills are used for aircraft wing and engine parts. The tool wear, static, and dynamic deformation caused by the flexibility of slender end mills hinder the productivity of such operations [56-58]. Tool wear is considered a tribological property, which propagates with the machining process and further increases surface roughness [59]. Tool wear directly affects the surface quality, tool life, dimensional accuracy, and economy of the machining process [60].

An important parameter in the milling process is the milling force. Milling force influences the power consumption in the cutting process and the design of machine tools, cutters, and fixtures. It is also an essential basis for selecting reasonable milling parameters. At the same time, it can measure the milling power and monitor the milling status. Milling force further has an important effect on cutting heat and thus affects tool wear, breakage, machining accuracy, and surface quality of machined workpiece [61]. The milling force can reflect not only the milling state in machining but also the lubrication performance of various cutting fluids. The improvement in lubrication performance decreases the cutting force and improves the cutting performance.

Aviation aluminum alloy materials are widely used in the aviation industry because of their high strength and toughness. However, large cutting force will cause tool deviation and vibration during the machining process, which result in tool wear; this condition influences the surface quality, tooling life, dimensional accuracy, and economy of the machining process [20]. Figure 3 shows the cutting mechanism and tool wear diagram.

\subsection{Influence on Workpiece Precision and Machining Quality}

The reliable and quantitative prediction of cutting force in the milling process is important to predict power, torque requirements, machine vibration, workpiece surface quality, geometric accuracy, and chatter-free cutting parameters [32]. Good machined surface quality plays an important role in the quality evaluation of aviation parts. Surface roughness, which is an essential index after machining, is the main reflection of different cutting parameters and system performance [62]. In the actual machining process, the modeling of milling force for high-strength thin-walled parts is challenging due to the variation of part and tool deflection and cutter shear angle, and the generation of milling force is a principal source of all machining errors.

The influence of tool eccentric runout and tool and workpiece deformation in the conventional milling process can be ignored, and the uncut thickness can be calculated only according to the feed rate of each tooth and the micro element position angle. Milling force is the key factor to characterize the machining process of thin-walled parts and is the basis of evaluating tool deformation, surface morphology, and cutting stability. It is widely used in machine tools, fixtures, tool design, tool wear monitoring, feed rate, other process parameter optimization, and machining deformation control. The milling of thin-walled workpiece requires high precision, has difficulty, and requires high cutting tools to consider tool runout, tool and workpiece deformation, tip cycloid trajectory, and size effect.

The research is mainly focused on the three-axis side wash machining of thin-walled parts with straight wall structure, such as frame and plate. The material removal 


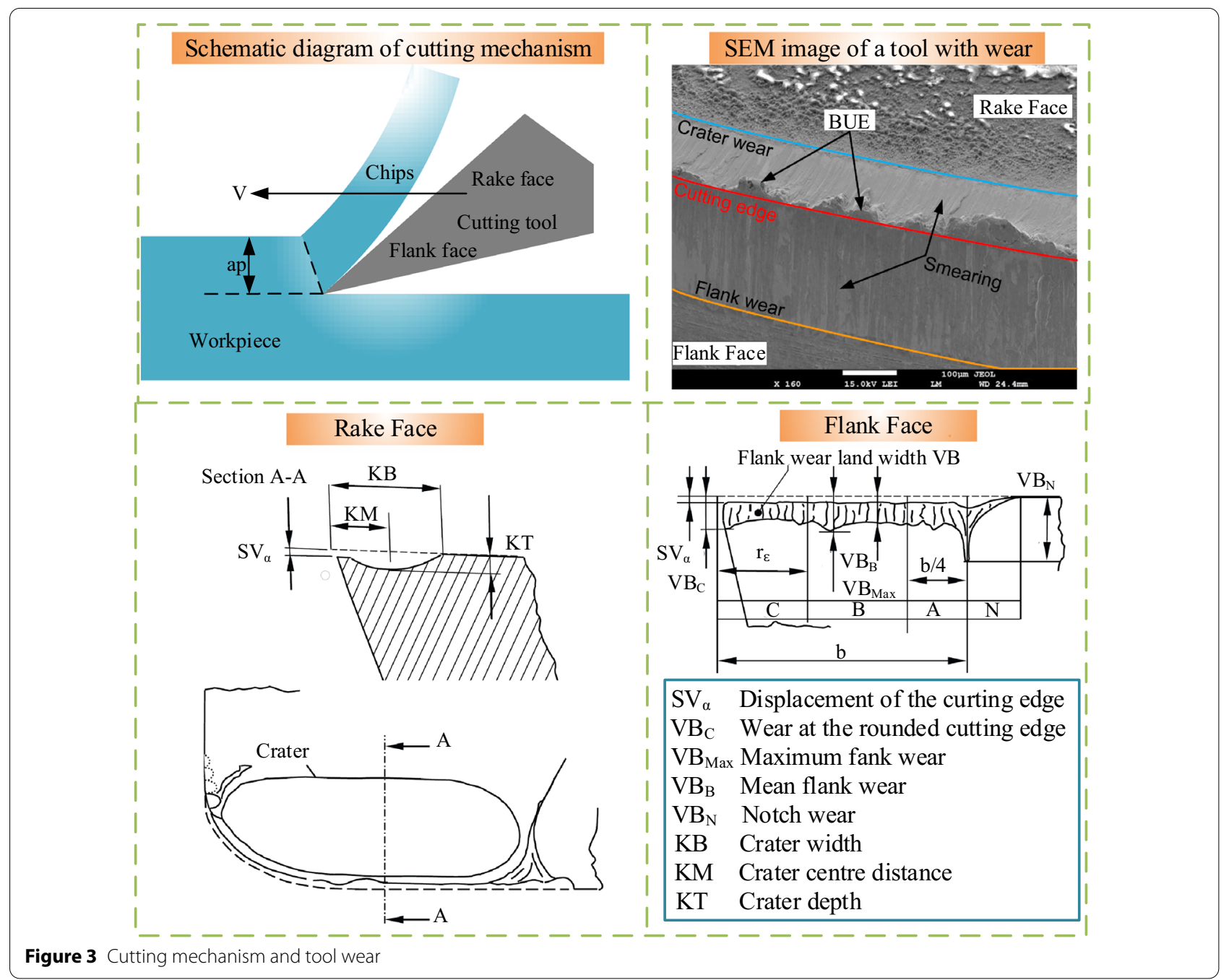

of curved surface parts is obviously different from that of flat plate parts. The influence of cutting parameters, tool parameters, and tool path on milling force of curved surface parts is unclear. High-performance thinwalled parts with complex curved surface are widely used, and higher requirements for machining accuracy and surface quality are put forward. Ball end milling cutter five-axis NC machining technology has been effectively used to achieve high performance and efficiency of complex surface production technology. However, these parts usually have complex surface, thin wall, and low stiffness. In addition, the time-varying instantaneous milling force in the process of five-axis machining often leads to deformation deviation between the actual machined and designed surfaces and even forms vibration marks and damage on the surface of the workpiece. This condition seriously affects the performance and stability of the product functional surface. Therefore, establishing an accurate milling mechanical model and analyzing the influence of milling force on the residual stress of arc plate parts by combining the cutting performance of workpiece material, geometric characteristics of workpiece/cutter, and process parameters are important.

\section{Empirical Model}

In the milling process, the empirical formula is mostly obtained through several cutting experiments. The establishment of the empirical formula needs the cutting force, cutting temperature, tool wear, and other data. The obtained data are analyzed by multiple linear regression method and MATLAB programming, and the function expression is established. This method is an effective cutting force prediction method, especially for the prediction of cutting parameters and cutting force data other than test data. 


\subsection{Process of Modeling}

Empirical modeling, namely, multiple regression analysis, is used to establish empirical formula by using a large number of experimental data. A group of coefficients in the empirical formula are used to roughly describe the relationship between milling parameters and force. The general method of empirical model is to use the tools with specific materials and geometric parameters to conduct milling experiments on a certain kind of difficultto-machine material workpiece under certain milling conditions and obtain a large number of experimental data. The undetermined coefficients are determined by statistical method $[63,64]$. The establishment process of empirical model is shown in Figure 4.

\subsection{Research Status}

According to the principle of metal cutting, a complex exponential relationship exists between the milling force and the cutting parameters under the premise of determining the geometric parameters of the machining materials and tools. Variance analysis method is used to determine the influence of spindle speed, axial cutting depth, radial cutting depth, feed speed, and other cutting parameters on cutting force. The basic formula of empirical model is expressed as Eq. (1) [65]:

$$
F=C_{F} n^{b_{1}} a_{p}^{b_{2}} a_{e}^{b_{3}} f_{z}^{b_{4}} z_{0} k_{F} d,
$$

where $n$ is the milling speed $(\mathrm{m} / \mathrm{min}), a_{p}$ is the axial cutting depth $(\mathrm{mm}), a_{e}$ is the radial cutting depth, $f_{z}$ is the feed speed $(\mathrm{mm} / \mathrm{min}), d$ is the milling cutter diameter $(\mathrm{mm}), z_{0}$ is the number of teeth in milling cutter, and $k_{F}$ is the correction factor.

In conventional end milling, Pan et al. [66] comprehensively considered the influence of milling parameters and tool helix angle on cutting force, applied the full factor experimental design and multiple regression analysis technology, took the spiral angle, axial, and radial cutting

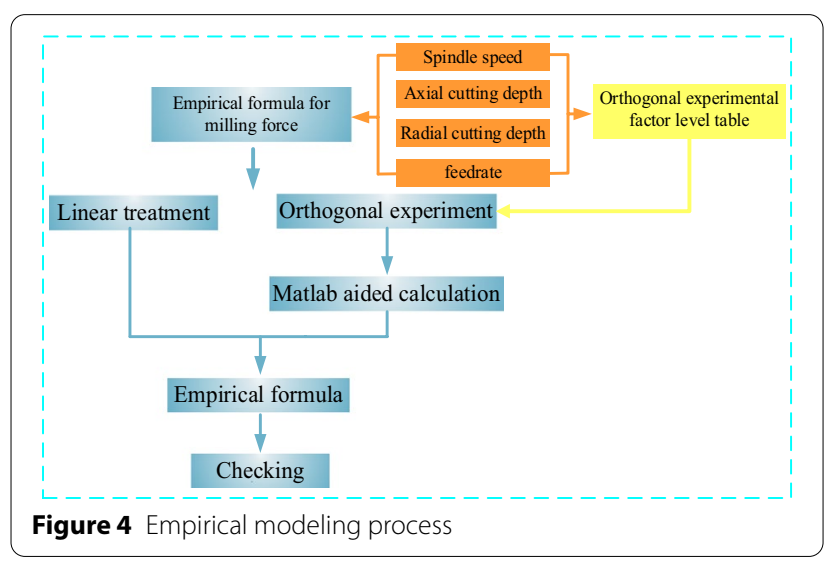

depth as input parameters, and adopted three-factor and three-level orthogonal test to establish the milling force prediction model of aviation aluminum alloy 7050-T7451. At the same time, Tang et al. [67] also established the empirical model of 7050-T7451 in the same way. The research results show that the milling depth has the greatest influence on the milling force, and it is followed by the feed rate and milling width per tooth. The least influence is exhibited by the milling speed. Different from the traditional empirical formula, Shao et al. [38] regarded milling speed as an independent factor, conducted four-factor and four-level orthogonal experiment on aluminum alloy 7050-T7451, and established an empirical model, which provides basis for tool design and cutting parameter selection.

Guo conducted milling experiment by using multifactor orthogonal test method, analyzed the experimental method of five factors and four levels by using matrix simplification method, and established an empirical model of CNC milling force for material 7075-T7351 [68]. The average error of $X$ direction milling force is $1.78 \%, Y$ direction average error is $1.425 \%$, and $Z$ direction average error is $6.61 \%$. Therefore, the proposed milling force model is applicable in the current processing equipment and environment, and the predicted theoretical value of each direction milling force is reliable. Wang et al. [69] used a 6-DOF robot to conduct high-speed milling experiments on aluminum alloy by the multi-factor orthogonal test method. A prediction model of aluminum alloy milling force was established on the basis of the principle of probability statistics and regression analysis.

Problems, such as cutter rebounding, cutter-drawing, overcutting, and processing deformation, often occur in the processing of aeronautical aluminum alloy thinwalled structural parts with low stiffness due to its small thickness. These problems affect the machining accuracy. Some scholars have established an empirical model of milling force to reasonably select milling parameters and optimize process parameters for addressing the abovementioned problems. Sun et al. [70] designed a milling orthogonal experiment according to the influence of milling depth, milling speed, feed rate, and milling cutter radius, analyzed the experimental, and established the empirical model of milling force for aluminum alloy 6061. The average error of milling force in $X$ direction is $3.8 \%$, that in $Y$ direction is $5.2 \%$, and that in $Z$ direction is $7 \%$. The empirical model also lays a solid foundation for further optimization of milling process parameters and deformation analysis of thin-walled parts.

The development of aerospace technology has made micro parts increasingly important, which brings new challenges to the fabrication of micromechanical 
structures with good surface quality, high-dimensional accuracy, and small machining error. Micro milling technology has been widely used at home and abroad because of its high machining accuracy, simple process, less material constraints, high processing efficiency, and ability to process complex 3D micro structures. Micro milling force is an important physical parameter in the study of micro milling process, and it has a direct effect on the generation of cutting heat, tool wear, tool life, and workpiece surface quality. At the same time, it is also an important basis for calculating cutting power, monitoring cutting process and tool working state, and designing machine tools, fixtures, and tools. Therefore, establishing a reliable micro milling force prediction model is important for machining parameter optimization, chatter prevention, and processing power demand prediction [71, 72]. In the research of micro milling, some scholars have established the empirical model of micro milling force by combining the traditional empirical modeling method. Zhang [73] established an empirical model of single peak value of micro milling force on cutting speed, spindle speed, and feed rate through orthogonal experiment of micro milling and achieved good prediction effect. On the basis of the relationship between tool wear and micro milling force, Bao [74] established an empirical model of the maximum amplitude of micro milling force on the milling distance and controlled the prediction error of micro milling force amplitude within $\pm 1.1 \mathrm{~N}$ or $3 \%$ by genetic algorithm.

The milling force of arc plate parts is a common problem in the field of aerospace. A deep and detailed understanding of the milling force in the milling process is important to ensure the machining accuracy and improve the machining efficiency. Zhang et al. [75] established the empirical model of arc edge end mill in machining aluminum alloy 2219 arc plate and obtained the variation law of milling force under different milling parameters through orthogonal experiment. Empirical models of milling force along arc line and generatrix of arc plate were built. The milling force empirical models of $F_{x}, F_{y}$, and $F_{z}$ when cutting along the arc line and generatrix of arc plate are shown in Figure 5. When cutting along the arc plate line, the milling force errors in the three directions are $3.86 \%, 2.65 \%$, and $4.42 \%$, respectively, all of which are less than $10 \%$. The empirical model of milling force for 2219 arc plate is applicable under the current working conditions. The milling force errors along the three directions of arc plate generatrix are $7.2 \%, 3.4 \%$, and $8.1 \%$, respectively. The error values in all directions are less than $10 \%$, which indicates that the predicted values of the model agree well with the experimental values.

The prediction method of the empirical model is to establish first- or second-order empirical formula by multiple regression analysis based on experimental data. The relationship between milling parameters and force is roughly described by a set of coefficients in the empirical formula.

The general method of modeling is to use the tools with specific materials and geometric parameters to conduct milling experiments on a certain kind of difficultto-machine material workpiece under certain milling conditions. Without considering the cutting mechanism and the material removal process, the mathematical law behind the cutting force and cutting parameters can be found. This model mainly considers the influence of cutting speed, feed per tooth, axial cutting depth, and radial cutting depth on milling force. Then, the final empirical formula is obtained by Taguchi orthogonal experiment. The model needs many experiments to collect a large number of experimental data for ensuring the accuracy of the fitting formula. The empirical model ignores the analysis of complex metal cutting theory, material shear, and friction in the milling process. The process of establishing the empirical model for predicting the milling

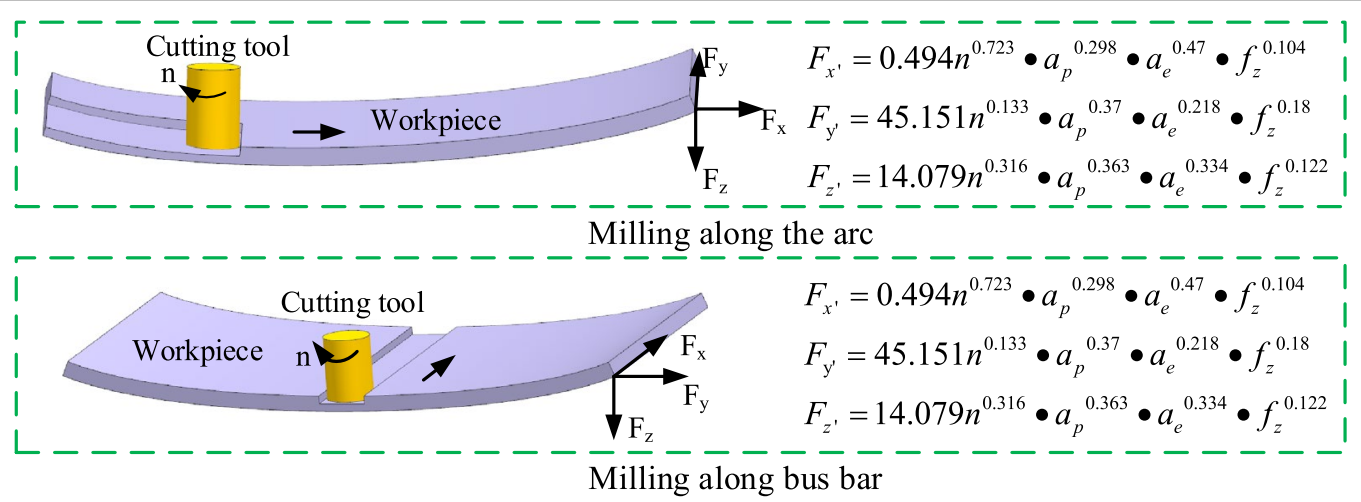

Figure 5 Milling along arc line and generatrix of arc plate [75] 
force of end mills is simple and pertinence, which is suitable for the parameter optimization in the actual mass production process. The establishment of an empirical model for predicting milling force must rely on several milling experiments. The accuracy of the prediction value depends on the number of coefficients, exponents, and experiments in the model. Table 1 shows the research status of empirical model of aviation aluminum alloy milling force.

\section{Finite Element Model}

In recent years, finite element method has become the main tool of metal cutting process simulation [76-78]. The rapid development of computer technology has facilitated the wide use of finite element numerical simulation method in cutting force modeling and prediction and chip forming and cutting residual stress analysis. This method has become effective in studying cutting mechanism and process optimization [79]. This numerical simulation method is appropriate for the analysis of elastic-plastic problems, including the analysis of temperature-related material performance parameters and large strain rate problems. It provides a new and more effective analysis method and approach for the systematic and indepth study of cutting mechanism and improvement in cutting quality. From the overall research results, most of them focus on the research of cutting mechanism and the effects of chip formation and chip deformation, tool wear and deformation, and chip accretion on cutting force and surface residual stress $[44,80,81]$.

Ozal et al. [82] simplified the straight tooth milling process by equivalent cutting layer simplification, simulated the milling force by orthogonal cutting model, and verified the correctness of the finite element model through cutting force experiment. Dong et al. [83] obtained the change in milling force in the process of helical tooth milling by establishing a 3D finite element model of oblique cutting process. However, the model also adopts cutting layer simplification and ignores the characteristics of variable cutting thickness in the milling process. Huang et al. [84] also studied the high-speed milling process of 7050-T7451 aluminum alloy and analyzed the influence of the tool rake angle, unloading angle, and feed rate per tooth on cutting force by adopting three-factor and three-level simulation scheme. Man et al. [85] proposed a 3D explicit dynamic Lagrangian finite element model and verified the force prediction ability of the model through the milling force data of aviation aluminum alloy Al7050-T7451.

Pham et al. [86] used the Mohr-Coulomb criterion plastic fracture model proposed by Bai and Wierzbicki to simulate the high-speed milling process of aluminum alloy A6061, as shown in Figure 6. The predicted cutting force is compared with the experimental results under the same cutting conditions to verify the model. The simulation results show that the accuracy of cutting force estimation can be significantly improved by adding the strain rate into the numerical model.

Gao et al. [87] introduced a 3D Eulerian finite element simulation model of end mill milling process based on ABAQUS/Explicit. The model is established by coupling Euler-Lagrange method, which makes the chip formation process independent of material degradation or continuous redrawing algorithm to realize chip separation. The process studied is groove milling of AL6061-T6. The model has good accuracy in cutting force prediction. The prediction error of comprehensive cutting force can be controlled within $12 \%$. Mebrahitom et al. [88] studied the side milling process of 6010 aluminum alloy and conducted numerical finite element simulation analysis of the side milling force by using the same method. Zhang et al. [89] established a numerical simulation model of 3D helical edge end mill milling 7055 aluminum alloy by finite element software Deform-3D. They also analyzed the influence of milling parameters, such as milling speed, feed rate, and milling depth, on milling force and milling temperature.

Table 1 Research on empirical model of milling force of aerospace aluminum alloy

\begin{tabular}{|c|c|c|c|c|c|c|}
\hline Ref. & Materials & Milling tool & Lubrication & Milling method & Milling type & Factor \\
\hline$[65]$ & ZL104 & Carbide end mill & Dry & Down & End face & $n, a_{p^{\prime}} a_{e^{\prime}} f_{z^{\prime}} d_{1} z_{0}$ \\
\hline$[66]$ & 7050-T7451 & Carbide end mill & Dry & Down & End face & $a_{p^{\prime}} a_{e^{\prime}} \beta$ \\
\hline [33] & 7050-T7451 & Carbide end mill & Flood & Down & End face & $a_{p^{\prime}} a_{e^{\prime}} n, f_{z^{\prime}} d$ \\
\hline [69] & 7050-T7451 & Carbide end mill & MQL & Down & End face & $f_{z^{\prime}} a_{p^{\prime}} a_{e^{\prime}} n$ \\
\hline$[38]$ & 7050-T7452 & Carbide end mill & Dry & Down & End face & $a_{p^{\prime}} a_{e^{\prime}} n, f_{z^{\prime}} d, z_{0}$ \\
\hline$[68]$ & $7075-7351$ & Carbide end mill & Dry & Down & Cavity & $a_{p^{\prime}} n, a_{e^{\prime}} f_{z^{\prime}} d, z_{0}$ \\
\hline$[70]$ & 6061 & Carbide ball end milling & MQL & - & Thin walled & $a_{p^{\prime}} n, f_{z^{\prime}} d$ \\
\hline$[75]$ & 2219 & Carbide arc-edged end mill & Dry & Down & Hook face & $n, a_{p^{\prime}} a_{e^{\prime}} f_{z^{\prime}} d_{1} z_{0}$ \\
\hline
\end{tabular}




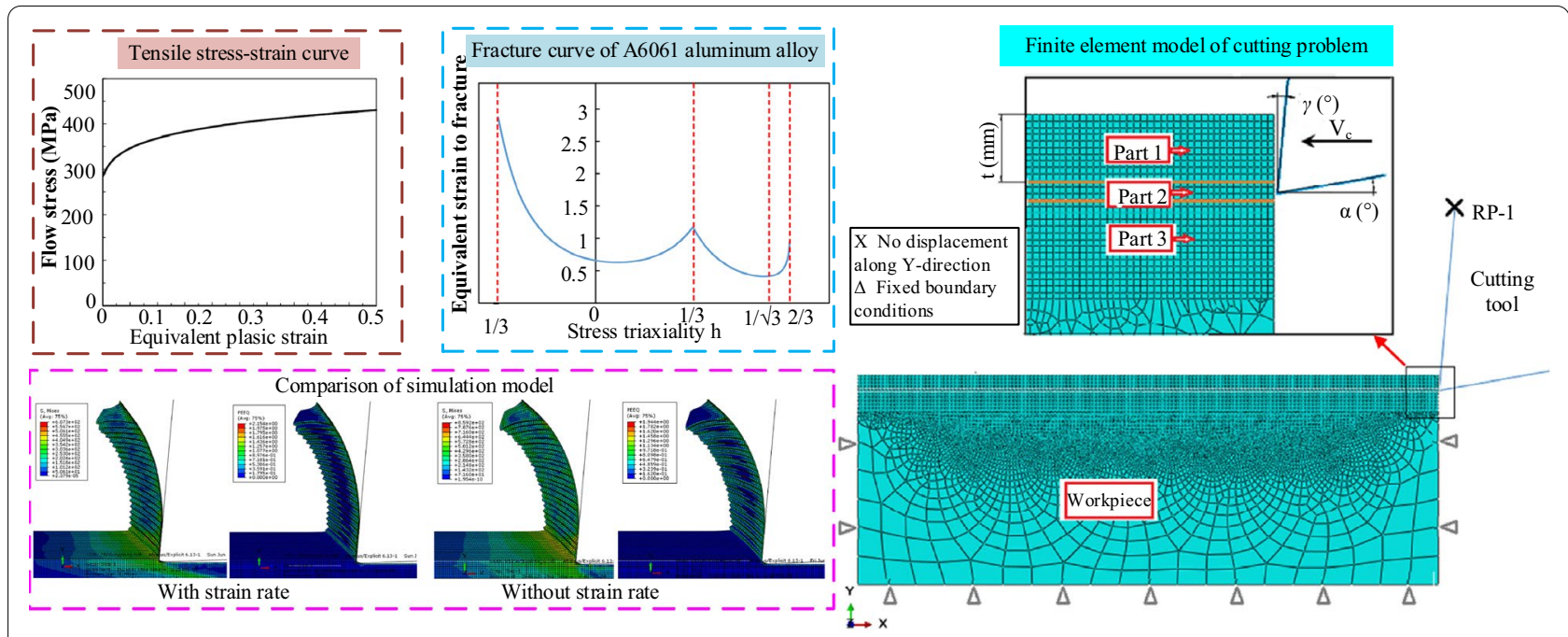

Figure 6 Finite element simulation of high speed milling of aluminum alloy A6061 [86]

For the finite element simulation of thin-walled parts, $\mathrm{Yu}$ et al. [90] applied the parallel motion load and rotation load to the tool model at the same time based on the analysis of the position relationship between the tool and the workpiece in the assembly model. They also established the milling finite element model of the sub cycloidal motion of the cutter. Ji et al. [91] established a milling dynamic model for aluminum alloy 7050-T7451 thin-walled parts. They further conducted finite element analysis through ABAQUS software to obtain the distribution law of milling stress and strain in the milling of aluminum alloy thin-walled parts. However, Wan et al. [92] proposed a general finite element method to predict the static forming error in cylindrical milling of thin-walled structures. This method has the advantages of discretization and flexibility of irregular finite element mesh. The effectiveness and flexibility of this method are demonstrated by numerical experiments on aviation aluminum alloy 7075-T6.

For aviation aluminum alloy micro milling, Liu et al. [93] used uncoated micro milling cutters with different cutting edge radii to perform groove milling on Al6061 workpiece. They also conducted 3D simulation and obtained the simulation cutting force. Sun et al. [94] used 7075-T6 aluminum alloy as the workpiece material, analyzed the changes of milling force and chip formation in the simulation process, and obtained the key process parameters of minimum undeformed chip thickness to study the mechanism of micro milling. Imania et al. [95] used simulation algorithm combined with finite element analysis to predict the dynamics of milling system, which considers the influence of tool deflection and runout. By milling 7075-T6 aluminum alloy with high-speed steel helical end mill, the model can accurately predict the cutting force and 3D surface texture of low radial immersion cutting.

Davoudinejad et al. [96] studied the machined minimum wall thickness using a finite element model to improve the understanding of the cutting mechanism and optimize the machining of aeronautic aluminum alloy Al6082-T6. Cai et al. [97] simulated the micro scale milling process of aluminum alloy 6061 by combining finite element simulation and single factor experiment and obtained the influence rule of milling speed and milling depth on milling force. Compared with the empirical model, the finite element prediction model can use the constitutive equation to express the properties of the materials. The bond and sliding models can be used to simulate the relative motion between the chip and the tool. The tool in the finite element simulation is an absolutely sharp rigid body, but the tool will have different degrees of wear in the actual milling process as the cutting process progresses. The machine tool in actual machining will vibrate due to the "dynamic balance effect." The finite element simulation is conducted under ideal conditions.

The success of the finite element simulation prediction model of milling force largely depends on the material constitutive and friction models between the cutter and the chip. The factors involved in the simulation of the cutting process and the output of the results are shown in Figure 7 [98]. Table 2 shows the comparison of cutting process simulation software. 


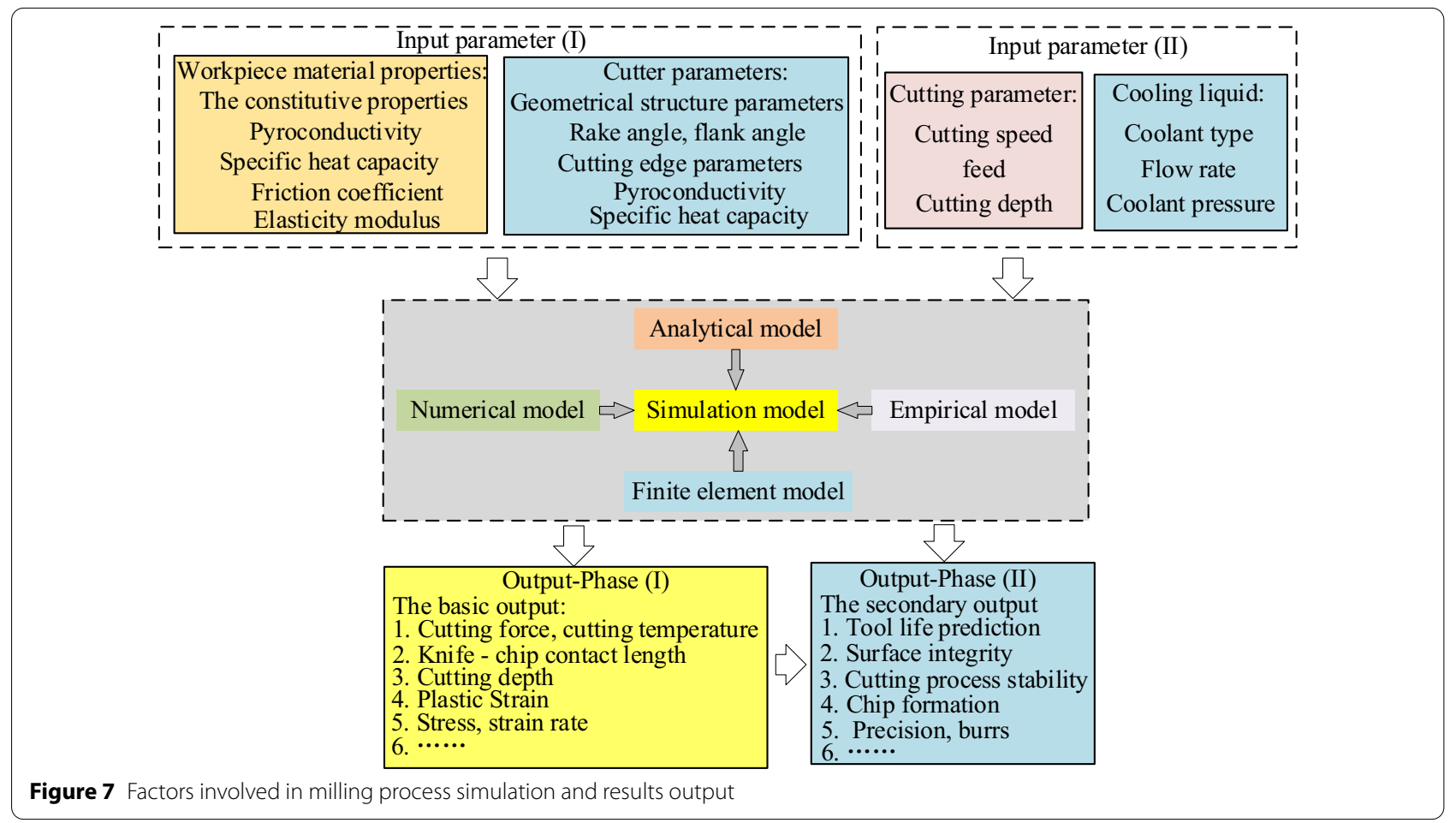

Table 2 Comparison of common cutting process simulation softwares

\begin{tabular}{|c|c|c|c|c|}
\hline Software & Algorithm & Analysis & CAE module & Application \\
\hline ABAQUS & $\begin{array}{l}\text { Lagrange } \\
\text { ALE } \\
\text { Euler }\end{array}$ & $\begin{array}{l}\text { Complex solid mechanics } \\
\text { Structural mechanics systems } \\
\text { Simulate the mechanics } \\
\text { Multi-physical field analysis }\end{array}$ & $\begin{array}{l}\text { Standard } \\
\text { Expicit } \\
\text { CAE } \\
\text { Design }\end{array}$ & $\begin{array}{l}\text { Mechanical processing } \\
\text { Metallurgy } \\
\text { Material processing } \\
\text { Civil engineering }\end{array}$ \\
\hline MARC & Lagrange & $\begin{array}{l}\text { Handle various linear } \\
\text { Nonlinear structure analysis } \\
\text { Modal analysis } \\
\text { Dynamic response analysis } \\
\text { Static and dynamic contact analysis }\end{array}$ & $\begin{array}{l}\text { Mentat } \\
\text { Parallet } \\
\text { Hexmesh }\end{array}$ & $\begin{array}{l}\text { Nuclear power } \\
\text { National defense } \\
\text { Aerospace } \\
\text { Automobile } \\
\text { Shipbuilding }\end{array}$ \\
\hline DYNA & $\begin{array}{l}\text { Lagrange } \\
\text { ALE } \\
\text { Euler }\end{array}$ & $\begin{array}{l}\text { High speed collision } \\
\text { Explosion and metal forming } \\
\text { Nonlinear problems of contact } \\
\text { Impact load and material }\end{array}$ & $\begin{array}{l}\text { Basic analysis } \\
\text { Kinetic Analysis } \\
\text { Nonlinear analysis } \\
\text { Heat conduction }\end{array}$ & $\begin{array}{l}\text { Automobile safety design } \\
\text { Weapon system design } \\
\text { Metal forming }\end{array}$ \\
\hline DEFORM & $\begin{array}{l}\text { Newton-Raphson } \\
\text { Explicit }\end{array}$ & $\begin{array}{l}\text { Environment integrated modeling } \\
\text { Heat conduction } \\
\text { Hot and cold molding }\end{array}$ & $\begin{array}{l}\text { Data analysis input } \\
\text { Mesh division and redivision } \\
\text { Data transfer calculation }\end{array}$ & $\begin{array}{l}\text { Forging } \\
\text { Rolling } \\
\text { Extrusion } \\
\text { Cold heading } \\
\text { Drawing } \\
\text { Moulding }\end{array}$ \\
\hline
\end{tabular}

\subsection{Material Constitutive Model}

The constitutive relation of the metal cutting process is related to many factors, such as strain, strain rate, and temperature [99, 100]. Liu et al. [101] compared MacGregor, Marusich, Zerilli-Armstrong, Johnson-Cook, and Usui constitutive equations. The
Johnson-Cook constitutive equation is simple in form and widely used in describing the stress-strain relationship of ferrous and nonferrous metals at large strain rates.

$$
\bar{\sigma}=\left(A+B \varepsilon^{n}\right)(1+C \ln \varepsilon)\left[1-\left[\frac{T-T_{\text {room }}}{T_{\text {melt }}-T_{\text {room }}}\right]^{m}\right],
$$


Table 3 Johnson-Cook constitutive equation coefficients of aeronautical aluminum alloys

\begin{tabular}{lllllcc}
\hline Reference No. & $\begin{array}{l}\text { The coefficients } \\
\text { of Johnson-Cook }\end{array}$ & $\boldsymbol{A}$ (MPa) & $\boldsymbol{B}$ (MPa) & $\boldsymbol{C}$ & $\boldsymbol{n}$ & $\boldsymbol{m}$ \\
\hline$[84]$ & Al7050-T7451 & 391 & 684 & 0.00959 & 0.436 \\
{$[105]$} & Al2007(100HB) & 320.9 & 316 & 0.0228 & 0.209 \\
{$[106]$} & Al6061-T6 & 324 & 114 & 0.002 & 0.42 & 0.9 \\
{$[104]$} & Al6082-T6 & 428.5 & 327.7 & 0.00747 & 1.008 \\
{$[107]$} & Al5083-H116 & 167 & 300 & 0 & 0.12 \\
{$[108]$} & Al2024-T3 & 325 & 414 & 0.015 & 0.2 \\
{$[109]$} & Al7075-T651 & 448.5 & 476 & 0.0012 & 0.31 \\
\hline
\end{tabular}

where $T$ is the deformation temperature $\left({ }^{\circ} \mathrm{C}\right), T_{\text {room }}$ is the room temperature $\left(20^{\circ} \mathrm{C}\right)$, and $T_{\text {melt }}$ is the melting temperature of the material. $A$ is the initial yield strength of the material at room temperature ( $\mathrm{MPa}), B$ is the strain hardening constant (MPa), and $\varepsilon$ is the strain. The parameter $n$ considers the strain hardening effect, the parameter $m$ models the thermal softening effect, and $C$ represents strain rate sensitivity, which can be obtained by material or cutting test method.

Hua et al. [102] studied the flow stress characteristics of aluminum alloy 7050-T7451 at high temperature and strain rate through split Hopkinson compression bar and quasi-static compression test. They obtained strain hardening parameters of the constitutive equation by using quasi-static experimental data. Guo [103] proposed a characterization method of mechanical behavior of processed materials based on the Johnson-Cook integral model. The parameters of the model are determined by fitting the data of quasi-static compression and machining tests. The quasi-static compression and processing tests of 6061-T6 aluminum verify the effectiveness of this method. Zel et al. [104] proposed a method to determine the deformation behavior of working materials under high strain rate metal cutting and used the evolutionary calculation method to identify the constitutive model parameters. Table 3 displays the Johnson-Cook constitutive equation coefficients of some aeronautical aluminum alloy materials.

\subsection{Friction Model between Tool and Chip}

As shown in Figure 8, two friction pairs between the tool and the workpiece, namely, the friction between the rake face and the flowing chip and the friction between the flank face and the machined surface, exist in the process of milling. For the contact between the rake face and the chip, Zorev [110] argued the existence of bonding and sliding zones. The normal and friction stresses acting on the rake face are distributed along the rake face, as shown in Figure 9. In the bonding zone, the shear stress is considered to be a fixed value, which is equal to the yield

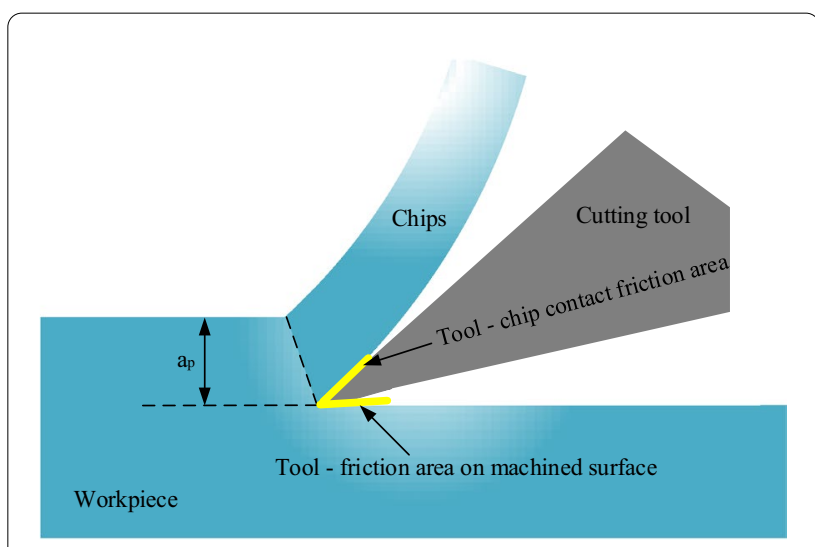

Figure 8 Schematic of friction area in cutting process

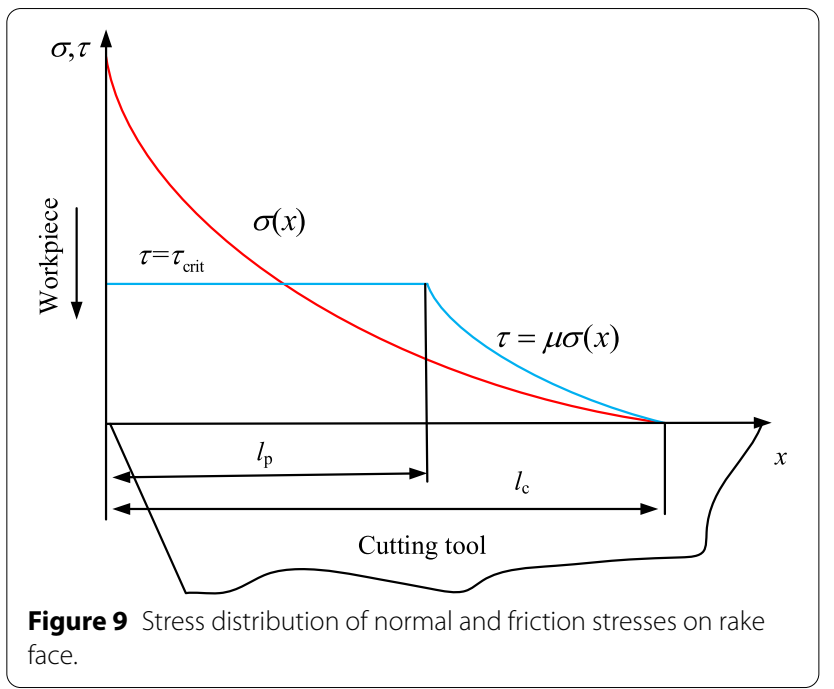

stress of the material; in the sliding zone, the friction coefficient $\mu$ is constant, which satisfies Coulomb's law of friction [111].

In the process of cutting simulation, researchers have generally used the friction model: 


$$
\left\{\begin{array}{l}
\tau_{f}=\mu \sigma_{n}, \tau_{f}<\tau_{\max }, \text { slip friction zone, } \\
\tau_{f}=\tau_{\max }, \tau_{f} \geq \tau_{\max }, \text { bonding friction zone, }
\end{array}\right.
$$

where $\tau_{f}$ is the frictional shear stress; $\tau_{\max }$ is the maximum shear stress of the material; $\sigma_{n}$ is the normal stress; $\mu$ is the friction coefficient, which takes the normal value of 0.1 .

Nonlinear exponential friction model is expressed as Eq. (4) [112]:

$$
\tau_{f} / \tau_{s}=1-\exp \left(-\lambda \sigma_{n} / \tau_{s}\right),
$$

where $\lambda$ is the material constant.

Friction model based on hardness is expressed as Eq. (5) [113]:

$$
\tau_{f}=\left(H_{v} / 0.07\right) \tanh \left(0.07 \mu \sigma_{n} / H_{v}\right),
$$

where $H_{v}$ is Vickers hardness of workpiece material.

An exponential model that considers temperature is expressed as Eq. (6) [114]:

$$
\tau_{f}=\tau_{f}\left(T_{\text {room }}\right) \exp \left(A_{0} / T\right),
$$

where $A_{0}$ is the material constant.

Model based on stress polynomial is expressed as Eq. (7) [115]:

$$
\tau_{f}=\sum_{i=0}^{4} a_{i} \bar{\sigma}^{i},
$$

where $a_{i}$ is the multinomial coefficient.

\section{Instantaneous Milling Force Model}

A deep and detailed understanding of the milling force in the milling process is necessary to ensure the machining accuracy and improve the machining efficiency. Yun et al. [116] established a milling force prediction model by fitting the coefficients of the model with measured experimental data. Desai et al. [117] established a 3D milling force model considering tool eccentricity runout by using implicit algorithm to calculate instantaneous cutting thickness. Montgomery et al. [118] proposed a furrow plough force model considering the friction between the tool flank and the workpiece. Rao et al. [119] analyzed the influence of curvature on the average milling force and established a milling force prediction model for circumferential milling of variable curvature curved surface. The cutting theory of Oxley has been applied to the analysis and calculation of milling force [120].

Most studies at present use differential discrete form to establish milling force model. The cutting edge is divided into several micro cutting edge elements along the axis, which are called micro element cutting edge or cutting micro element. The force acting on micro element cutting edge is called micro element cutting force. Each element is in oblique cutting state, and the total milling force is the vector sum of micro element cutting force [121-124]. The milling force model established by this method mainly includes three parts: micro element milling force model, milling force coefficient, and milling thickness model.

Accurate milling force model is essential for better understanding of machining parameters and better control of machining output (e.g., surface error, vibration, and tool wear). Figure 10 shows the process of establishing the instantaneous milling force model.

\subsection{Uncut Chip Thickness}

Instantaneous cutting thickness is another important parameter in the analytical model of milling force. Instantaneous cutting thickness is only related to feed rate and micro element position angle in ideal state. However, the tool eccentric runout and the deformation of the tool and the workpiece in the actual machining process will cause the change in the instantaneous cutting thickness, the instantaneous position angle of the micro element, and the contact area between the tool and the chip. As a result, the instantaneous milling force changes. The change in milling force feedback affects the deformation of the tool and workpiece.

Martellotti showed that the true path of a cutter tooth is trochoidal and that the chip length in conventional milling is longer than that in climb milling. Several chip thickness formulas are derived by Martellotti, and the most basic equation is expressed as Eq. (8) [125].

$$
h=f_{z} \sin \theta,
$$

where $h$ is the instantaneous chip thickness, $f_{\mathrm{z}}$ is the feed (in/tooth), and $\theta$ is the angular position of a tooth in the cut. This equation for chip thickness is commonly used in the analysis of the milling process.

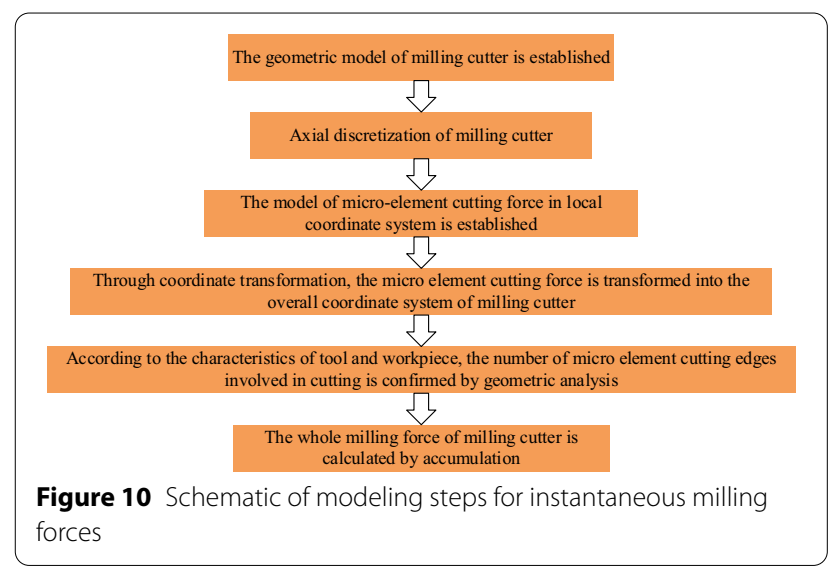


Eq. (8) can easily predict the cutting force but will sacrifice some accuracy because it only reflects the tool geometry and feed per tooth. Yun et al. [126] calculated the uncut thickness by tracking the movement of the tool, and the geometric calculation is shown in Figure 11.

Abele et al. [127] presented a method based on a stateof-the-art milling model by utilizing a different identification method using the instantaneous chip thickness. This method requires only one cutting test at a fixed feed rate and provides better results in terms of the average error. Pang et al. [128] considered that the instantaneous uncut thickness is determined by the angle position and tool runout. Then, the cutting force and thrust are calculated according to the instantaneous chip load. The milling experiment of aluminum alloy Al7075 was conducted for verification. Niaki et al. [129] developed a new method to simulate chip thickness at low to medium cutting speed. They found that tool path cannot be described as pure circle path, but a real cycloid model is needed.

Milling is an effective technology to realize the manufacturing of micro parts with complex structure and diversity of materials and has an increasingly broad application prospect. However, micro milling has a significantly different processing mechanism from traditional milling due to the sharp reduction of tool size and processing parameters.

The first is the size effect. The tool in macro cutting is considered to be absolutely sharp. However, the cutting feed rate in the field of micro machining is equivalent to the rounded radius of the cutting edge of the tool. Thus, the phenomenon of rounded radius of the cutting edge can no longer be ignored, which results in plough cutting and minimum chip thickness phenomena. Second, tool runout considerably affects the cutting process. Tool runout is common in the process of micro milling. Tool runout is defined as the inclination of tool axis with machine tool fixture and spindle system axis, namely, tool angular runout, and on the basis of parallel, tool axis relative to machine tool fixture and spindle system axis radial offset, namely, tool radial runout. The abovementioned two kinds of tool runout will cause the tool center to deviate from the theoretical position. The main causes of tool runout include (1) manufacturing error of the machine tool spindle and fixture system, (2) manufacturing error of cutting tool, (3) installation error of cutter, and (4) wear of tool in machining. Tool runout is the principal factor restricting the quality of micro cutting. The tool runout in micro cutting is equivalent to the feed rate of each tooth. This condition brings serious instability to the cutting process and even leads to a certain tooth empty cutting. Two-teeth cutter easily forms single tooth cutting phenomenon. Therefore, the accuracy and reliability of cutting force modeling are directly related to the accuracy and reliability of cutting force modeling and then affect the quality control of micro cutting.

Accurate modeling of instantaneous undeformed chip thickness is a fundamental problem in micro cutting mechanics. Li et al. [130] derived the actual cutting area in micro cutting, considered the cutting path of all passing teeth in a cycle, and proposed a universal instantaneous undeformed chip thickness model. Bao et al. [131] considered not only the cycloid path of the tool tip during continuous rotation and forward movement but also the tool runout when calculating the instantaneous undeformed chip thickness in micro milling. Sahoo et al. [132] presented an improved undeformed chip thickness algorithm by considering tool run out, minimum chip thickness, and trajectory of all passing teeth for one complete revolution of the tool instead of only the current tooth trajectory. Wojciechowski et al. [133] analyzed the proposed original force model, which considers the micro end milling kinematics, geometric errors of the machine tool-toolholder-mill system, elastic and plastic deformations of workpiece correlated with the minimum uncut

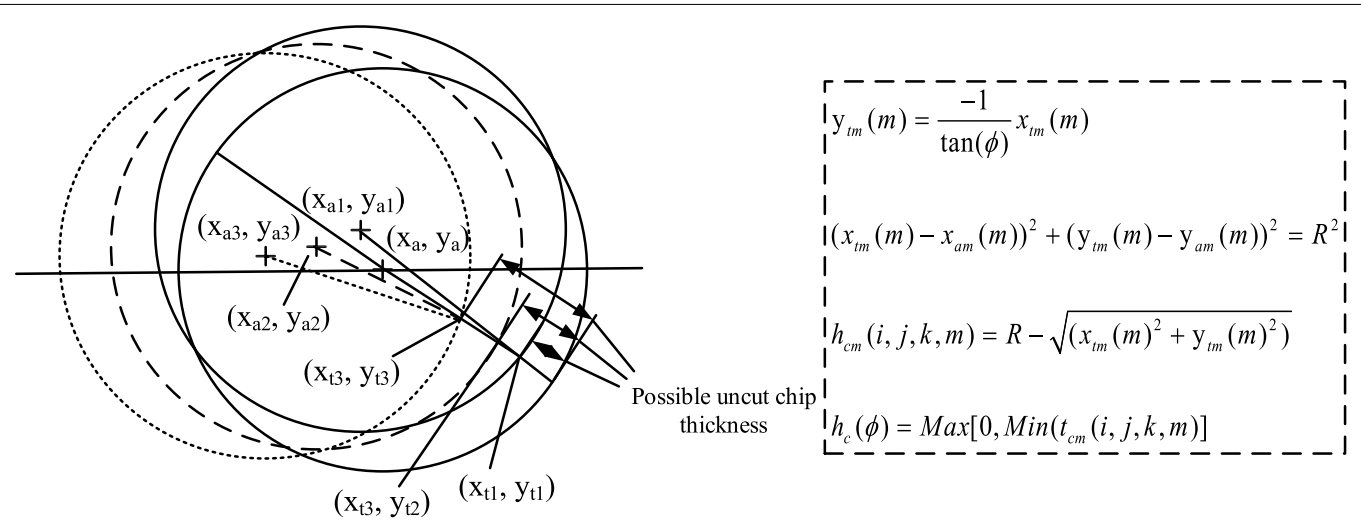

Figure 11 Uncut chip thickness calculation geometry [126] 
chip thickness, and flexibility of the slender micro end mill. Jun et al. [134] introduced the elastic recovery of the machined workpiece and dynamic characteristics of the micro milling tool to instantaneous undeformed chip thickness model. They also acquired a precise prediction of cutting force in micro milling operation. The size effect has a certain error effect on the precision of micro milling force. However, the abovementioned researchers have ignored the size effect. Rodríguez et al. [135] established instantaneous undeformed chip thickness model for twoteeth micro milling operation by considering tool runout, too deflection, size effect, and asymmetric cutting. Then, the cutting forces were simulated. The results show satisfactory agreement with the data from micro milling experiments.

Kumanchik et al. [136] developed dimensionless analytical expressions for uncut chip thickness, entry and exit angle considering cycloidal motion of cutting tooth, cutter runout, and uneven tooth spacing. The model shows lower error in computation of the uncut chip thickness than the models developed earlier. As shown in Figures 12 and 13, Zhang et al. [137] developed an uncut chip thickness model for micro end milling. This model considers the calculation of variable inlet and outlet angles caused by tool runout and deflection. In this model, the actual instantaneous uncut thickness is evaluated by considering the theoretical instantaneous uncut thickness, the minimum uncut thickness, and a critical chip thickness related to the material removal mechanism. The results demonstrate that the proposed method can achieve high consistency between the model and experimental forces. Kang et al. [138] estimated the chip thickness in micro end milling by summing the thickness of conventional and additional chip components and then expressed the thickness by the Fourier series. Dib et al. [139] proposed a method to determine the minimum chip thickness based on the influence of cutting force signal change and tool radial runout on chip formation. The milling force of aluminum alloy Al6061-T6 was tested with uncoated cemented carbide micro end

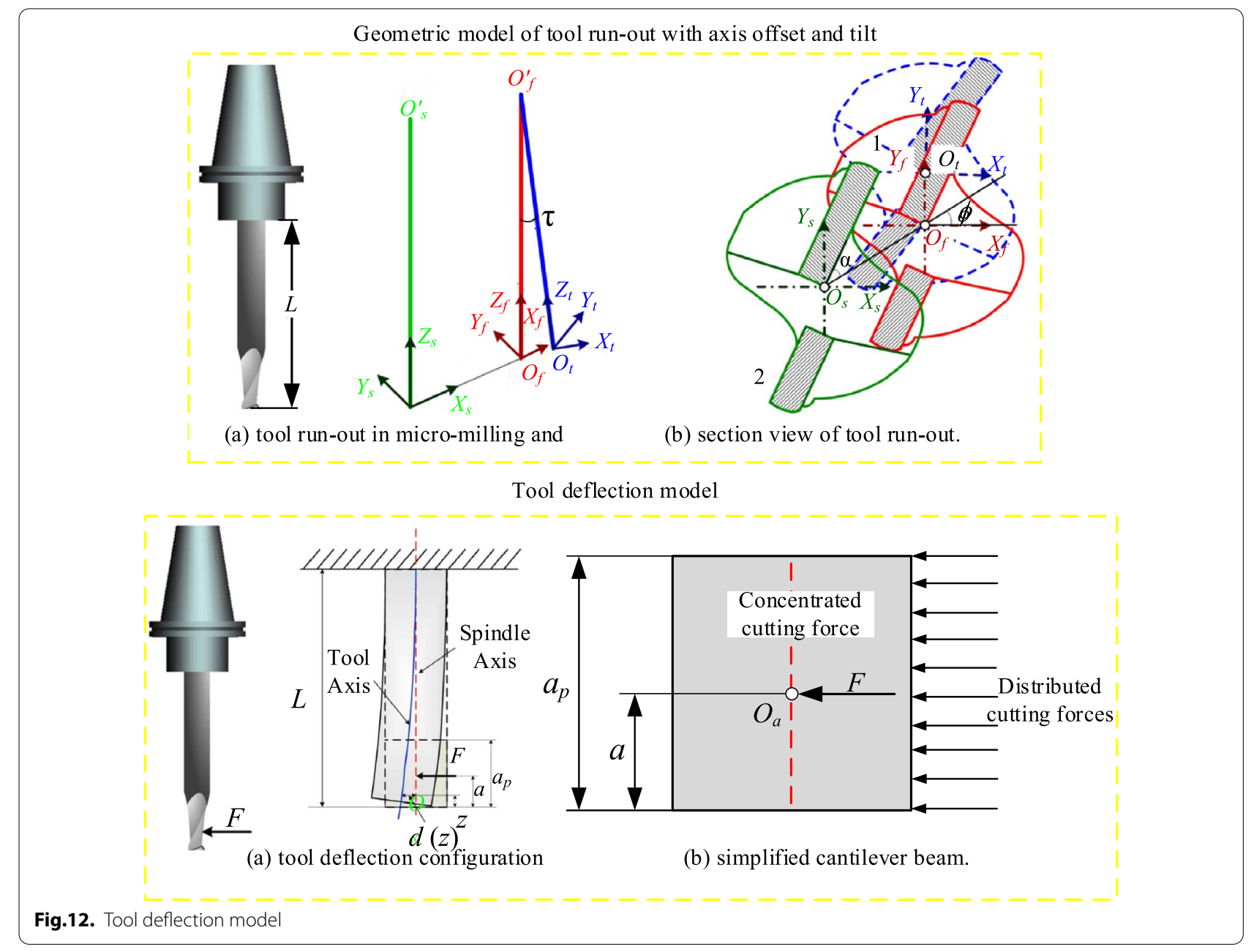




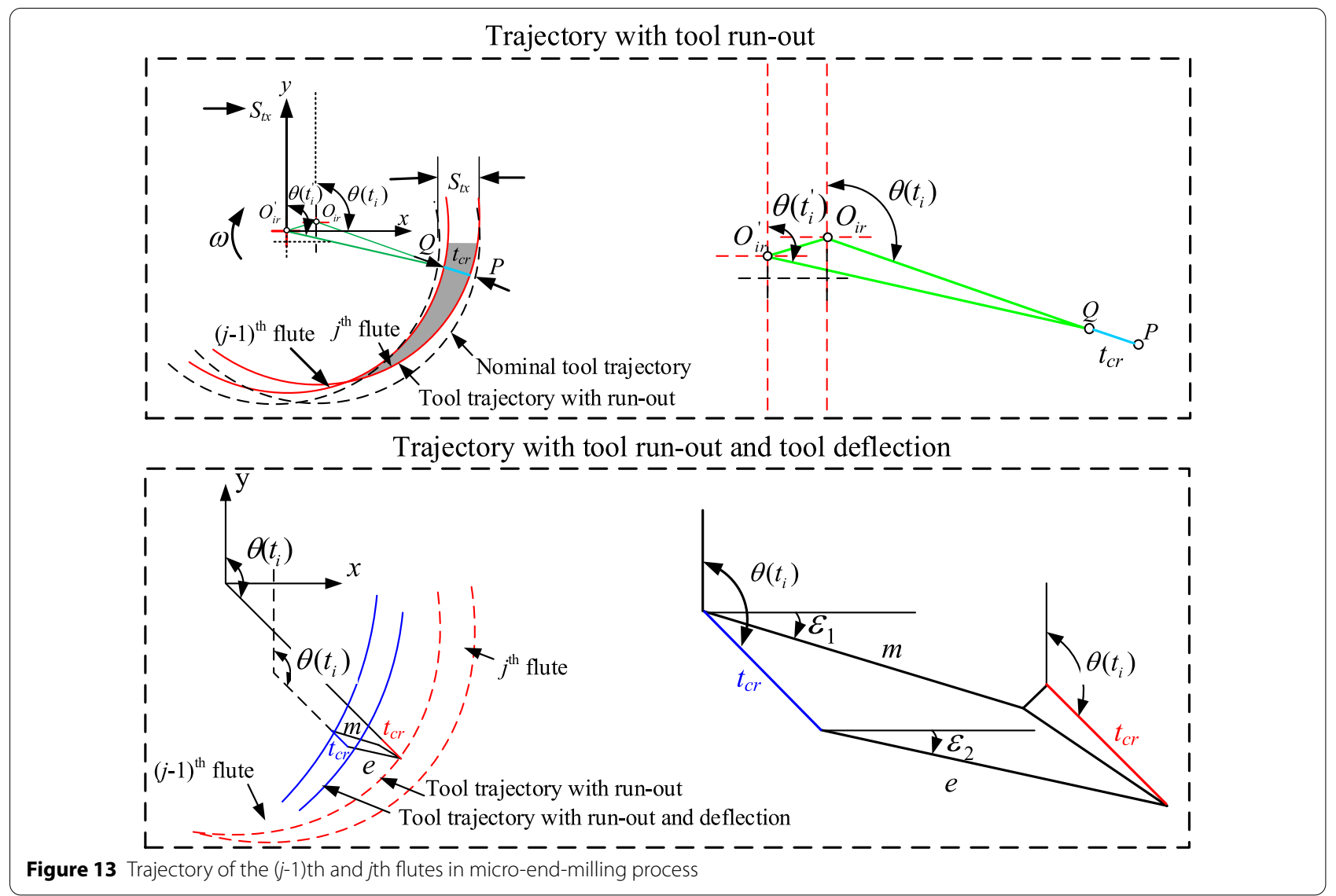

mill. Wan et al. [140] believed that ploughing force is an item independent of the uncut chip thickness in the traditional milling force model, which cannot be applied to micro milling. Therefore, a new method is proposed to study the effect of cutting edge radius on micro milling and ploughing effect caused by uncut chip thickness for establishing cutting force model in micro milling process.

The milling of thin-walled parts, such as girders and aeroengine blades, is widely used in the aerospace industry. However, the geometric complexity of parts and the extreme machining performance of materials are challenging the current manufacturing capacity. Wan et al. [141] established a set of system programs to simulate the peripheral milling process of thin-walled workpiece, which integrates the cutting force module composed of calculation of instantaneous uncut chip thickness, calibration of instantaneous cutting force coefficient, and cutting process module composed of calculation of cutting structure and static shape error, as shown in Figure 14. This method can be used to verify the rationality of the process and optimize the process parameters in the high-precision milling process.

For the arc plate parts, Zhang et al. [75] established a model that the instantaneous cutting thickness changes with the change in cutting edge position when the arc edge milling cutter is used to mill the arc plate. Figure 15 shows a schematic of the cutting edge geometry and cutting load of the circular edge milling cutter.

Feng et al. [142] discretized the ball end milling cutter into circular slices horizontally and described it with a plane end milling model with different diameters. The approximate model of undeformed chip thickness in machining curved surface with ball end cutter is expressed as Eq. (9):

$$
h(\theta, z)=R_{2}(z)-R_{1}(z)+f_{z} \sin \theta,
$$

where $R_{1}$ and $R_{2}$ represent the actual radii of the cutting elements at the same axial height. Imani et al. [143] considered that the extraction of instantaneous chip thickness from the accurate representation is computationally inefficient. Thus, they used a modified Eq. (10) that can accurately calculate this chip thickness at any angular position:

$$
h(\theta, z)=R_{2}(z)+f_{z} \sin \theta-\sqrt{R_{1}^{2}(z)-f_{z}^{2} \cos \theta} .
$$

Desai et al. [144] proposed a mathematical model for calculating the geometric parameters of tool/workpiece 


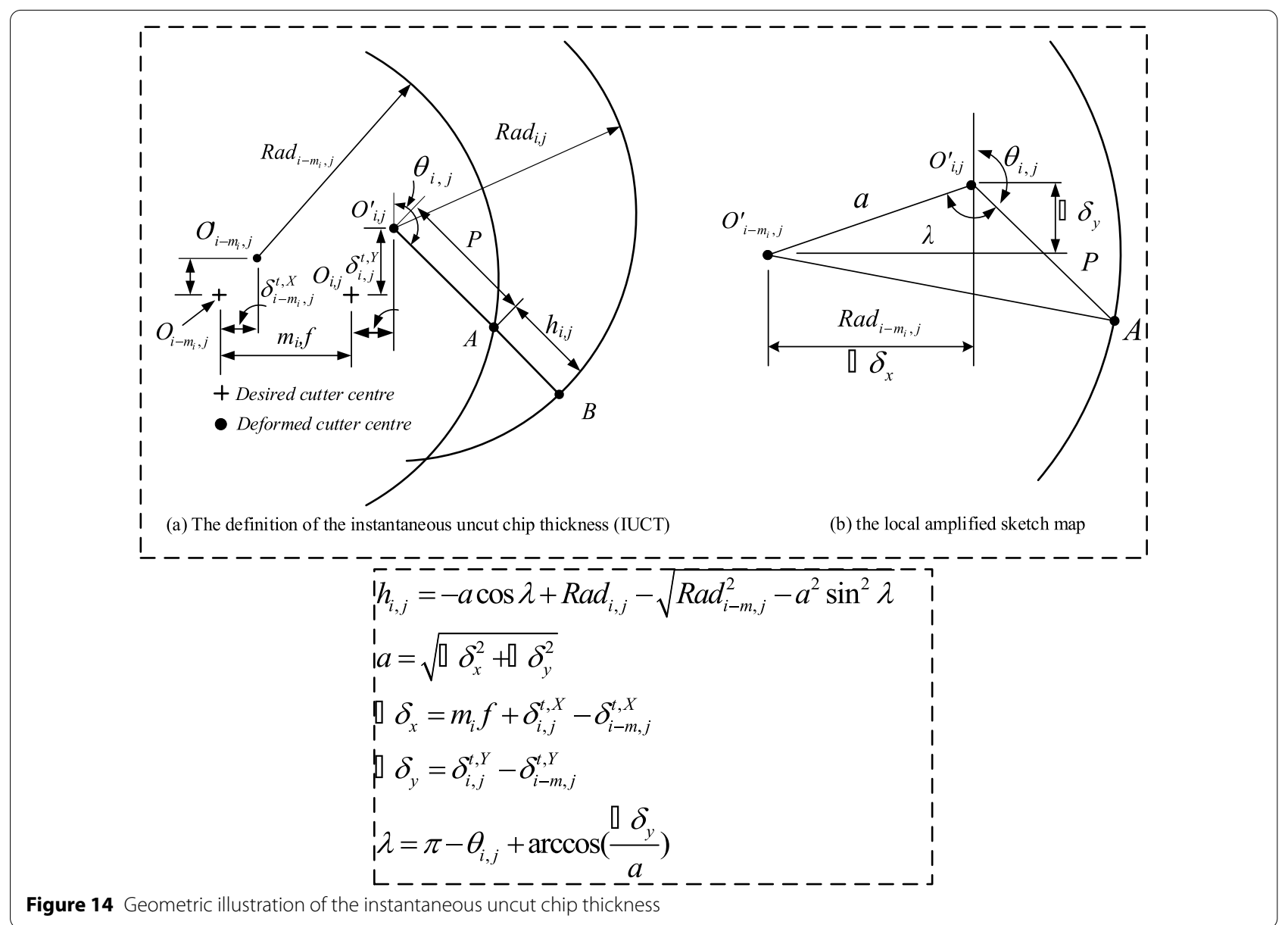

engagement and instantaneous uncut chip thickness during tool runout for curved surface milling. The model considers the interaction between the cutting and front tooth paths in the calculation process geometry, which is more in line with the actual situation. Hao et al. [145] derived a new formula of undeformed chip thickness including tool eccentricity runout by using coordinate transformation method. The validity of the model was verified by milling aviation aluminum alloy Al6061-T6. The influence of curvature on cut in angle, cutting angle, undeformed chip thickness, feed direction force, and normal force was also analyzed. Ko et al. [146] proposed a cutting force model of ball end milling cutter based on instantaneous cutting force coefficient. The uncut chip thickness model of the model considers the tool deflection and runout. Wang et al. [147] modeled the effect of tool runout as an additional machining feed, which produces cyclic changes in the uncut chip thickness. For the tool vibration, the differential motion equation was solved using the measured modal parameters to obtain the real-time vibration of the tool in the machining process. Lotifi et al. [148] established analytical models of three-axis and five-axis ball end milling cutter workpiece meshing area and instantaneous undeformed chip thickness based on real tooth profile trajectory and machined surface geometric characteristics. The parameters considered in the model include the inclination angle, lead angle, feed per tooth, cutting depth, stride, cutting speed, tool runout, and return angle. The milling verification of aluminum alloy 7075-T6 was conducted.

According to the research in Table 4, the accurate modeling of instantaneous undeformed chip thickness is a key issue studied by scholars. The instantaneous cutting thickness is only related to feed rate per tooth and micro element position angle in ideal condition. However, in the actual machining process, the tool eccentric runout, the tool and workpiece deformation, and the tip cycloid trajectory will cause the instantaneous cutting thickness, the micro element instantaneous position angle, and the contact area between the cutter and the chip change, which will cause the instantaneous milling force change. The milling force change feedback also affects the tool and workpiece deformation. In the conventional milling process, we can ignore the influence of tool eccentricity and tool and workpiece deformation and calculate the uncut thickness only according to the feed rate of each tooth and 


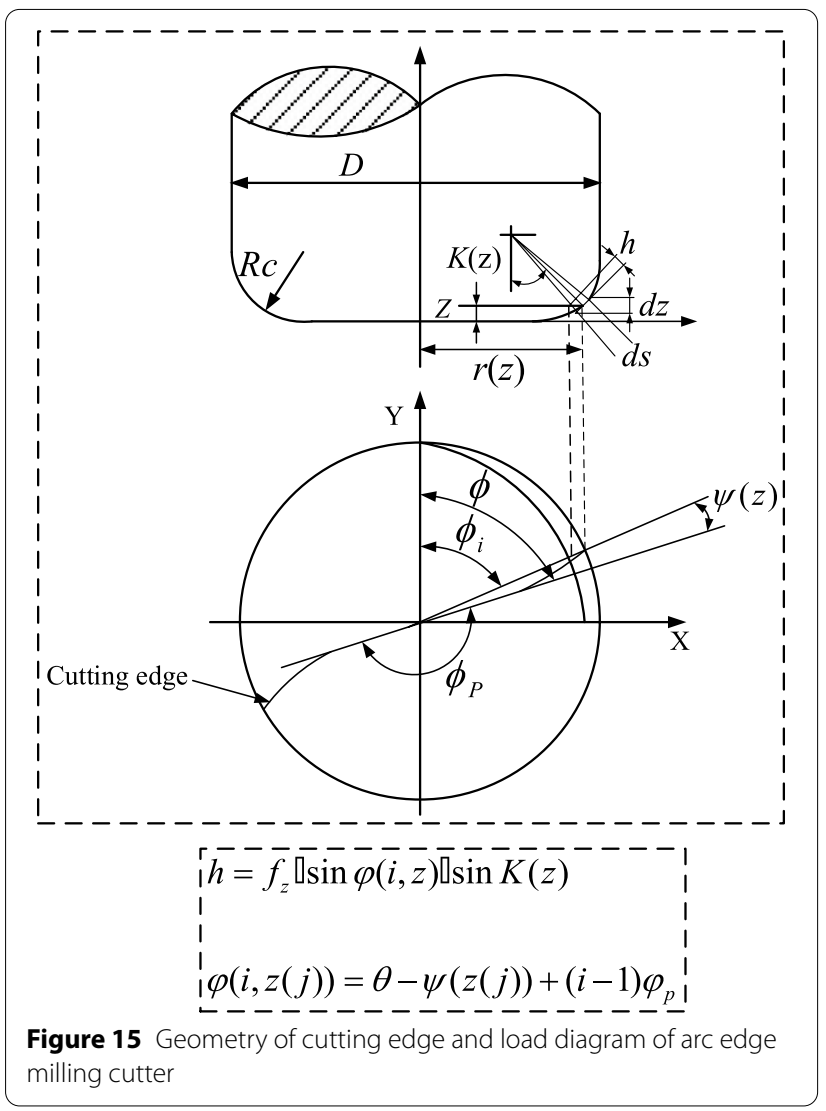

the micro element position angle, as shown in Eq. (8). Factors, such as tool eccentricity runout, tool and workpiece deformation, tool tip cycloid trajectory, and edge size effect, cannot be ignored because the diameter of micro milling tool varies from $25 \mu \mathrm{m}$ to $1.0 \mathrm{~mm}$. These factors further affect the prediction of cutting force and surface roughness. For complex surface machining, the prediction of cutting force and machining surface error is important because of the change in workpiece curvature along the tool path. The complexity is caused by the change in process geometry structure when the workpiece curvature changes along the tool path. Other reasons are tool runout, workpiece curvature effect, and tooth rail interaction. Therefore, the accuracy of the spatial position of any micro element cutting edge is required.

\subsection{Micro Element Milling Force Model}

The research on this mechanical model is usually based on the research idea of Martellotti in 1941, that is, the milling force is calculated by cutting load [149]. The micro element cutting force component in machining process is expressed as the product of cutting force coefficient and cutting micro element area. The concrete expression form of micro element milling force model can be divided into two main types. Type I assumes that the milling force is a function of the undeformed chip section area and uses a single group of cutting force coefficients to express the

Table 4 Research literatures on cutting thickness of aerospace aluminum alloy

\begin{tabular}{|c|c|c|c|c|}
\hline Year & Conventional end milling & Micro milling & $\begin{array}{l}\text { Thin-wall } \\
\text { workpiece }\end{array}$ & curved-surfaces \\
\hline 1961 & Milling parameters [121] & & & \\
\hline 1981 & Feed speed [125] & & & \\
\hline 1994 & & & & Tool parameters [142] \\
\hline 1996 & Feed speed [46] & & & \\
\hline 1998 & & & & Tool parameters [143] \\
\hline 2000 & Tool path [126] & Tool runout [131] & & \\
\hline 2001 & Structural vibrations [47] & & & \\
\hline 2006 & & Elastic recovery [134] & & \\
\hline 2007 & Feed rate $[48]$ & Tool runout [132] & & \\
\hline 2008 & & & $\begin{array}{l}\text { Cutter/workpiece } \\
\text { deflections [141] }\end{array}$ & \\
\hline 2009 & Feed; penetration angle [127] & Elastic recovery [133] & & Tool runout [117] \\
\hline 2010 & Tool path [49] & & & \\
\hline 2013 & & Tool runout; size effect [135] & & \\
\hline 2014 & & & & Tool runout [145] \\
\hline 2015 & Angular position; tool runout [128] & & & Tool vibrations and runout [147] \\
\hline 2016 & & Tool deflection $[130,137]$ & & Tilt and lead angles [148] \\
\hline 2017 & Tool path [129] & & & \\
\hline \multicolumn{5}{|l|}{2018} \\
\hline 2019 & & Cutting edge radius [140] & & \\
\hline 2020 & & Tool runout; elastic recovery [72] & & \\
\hline
\end{tabular}


shear extrusion and friction effects acting on the rake and flank faces. Type I is expressed in the form of $F_{t}-F_{\mathrm{r}}-F_{\mathrm{a}}$ (tangential, radial, and axial forces).

$$
\left\{\begin{array}{l}
\mathrm{d} F_{t}=K_{t} h \mathrm{~d} z, \\
\mathrm{~d} F_{r}=K_{r} h \mathrm{~d} z, \\
\mathrm{~d} F_{a}=K_{a} h \mathrm{~d} z,
\end{array}\right.
$$

where $K_{t}, K_{r}$, and $K_{a}$ are three cutting force coefficients. $h$ is the instantaneous uncut chip thickness. $\mathrm{d} z$ is the differential length in cutter axis.

The form is $F_{n}-F_{f}$ (positive pressure and friction).

$$
\left\{\begin{array}{l}
F_{n}=K_{n} \mathrm{~d} A_{c}, \\
F_{f}=K_{f} \mathrm{~d} A_{c},
\end{array}\right.
$$

where $K_{n}$ and $K_{f}$ represent the coefficient of positive pressure and friction.

Ploughing force exists in addition to shear force in the milling force component in type II, and the shear and ploughing forces are expressed separately. Two groups of different cutting force coefficients (shear and ploughing force coefficients) are used to represent the cutting force $[52,150,151]$. The form is $F_{t}-F_{r}-F_{a}$ (tangential force, radial force, and axial force):

$$
\left\{\begin{array}{l}
\mathrm{d} F_{t}=K_{t c} h \mathrm{~d} z+K_{t e} \mathrm{~d} S, \\
\mathrm{~d} F_{r}=K_{r c} h \mathrm{~d} z+K_{r e} \mathrm{~d} S, \\
\mathrm{~d} F_{a}=K_{a c} h \mathrm{~d} z+K_{a e} \mathrm{~d} S,
\end{array}\right.
$$

where $\mathrm{d} F_{t}, \mathrm{~d} F_{r}$, and $\mathrm{d} F_{a}$ (in $\mathrm{N}$ ) are the tangential, radial, and axial force components. $K_{t e}, K_{r e}$, and $K_{a e}$ (in $\mathrm{N} / \mathrm{mm}$ ) are the edge-specific coefficients, $\mathrm{dS}$ is the length of micro element cutting edge, $\mathrm{d} z$ is the thickness of each element (mm), and $K_{t c}, K_{r c}$, and $K_{a c}$ (in $\mathrm{N} / \mathrm{mm}^{2}$ ) are the shear-specific coefficients.

The form is $F_{n}-F_{f}$ (positive pressure and friction):

$$
\left\{\begin{array}{l}
F_{n}=K_{n s} \mathrm{~d} A_{c}+K_{n e} \mathrm{~d} S, \\
F_{f}=K_{f s} \mathrm{~d} A_{c}+K_{f e} \mathrm{~d} S .
\end{array}\right.
$$

The micro element cutting force model of the theoretical mode is a micro element cutting force model based on a certain metal cutting theory from the perspective of theoretical analysis. However, the modeling process is complex due to the influence of various factors, such as heat, force, and strain hardening. In the actual modeling, several assumptions and simplifications are conducted to reduce the difficulty of modeling.

Jayaram et al. [152] proposed a method based on type I to estimate the specific cutting pressure using Fourier transform of zero-frequency cutting force data. The effectiveness of this method is verified by cutting experiments of aviation aluminum alloy 2024 with single blade and multi blade. Wan et al. [153] established a unified method to identify the cutting force coefficient and tool runout parameter of ordinary end mills (cylindrical, ball, and bull head milling cutters). Thereafter, Wan et al. [154] conducted mathematical derivation and realization based on measured cutting force or Fourier transform harmonic. The modeling method of cylindrical milling force with tool runout is studied systematically. Effectively calibrating the cutting force coefficient and tool runout is considered. In addition, the experimental verification of aviation aluminum alloy 7050 is performed using three-edge carbide flat milling cutter.

The abovementioned researchers have mainly studied the cutting thickness and milling force coefficient on the basis of type I model and established instantaneous milling force model, while type I mainly focuses on shear force. With the increasing requirements for the machining accuracy and requirements of structural parts, many researchers have argued that ploughing force exists in addition to shear force in the components of milling force, especially for thin-walled workpiece milling and micro milling. A size effect that changes faster than the milling coefficient, which is due to very small milling thickness, exists. Thus, plough force needs to be considered. In type II, ploughing force exists in addition to shear force in the component of cutting force.

Junz et al. [155] established the force analysis model of shear and plough mechanism in end milling process using type II as the basic formula. The analytical models of milling force in angle and frequency domains are derived by convolution method and Fourier transform, respectively, which are expressed as the superposition of shear and ploughing forces. The results show that the plough force in the model has good prediction accuracy, and the Al2024-T4 is verified by experiments. Shirase et al. [156] considered the stiffness values of spindle, tool holder, and chuck and tool stiffness parameters, studied the change in chip load and deflection distribution of each tooth cycle, and estimated the cutting force. The groove milling experiment of Al7075 is conducted under the condition of dry milling. Some researchers have used the generalized mathematical model to analyze the cutter geometry and establish the milling force model suitable for various types of cutting tools. Engin et al. [47] used the real kinematics of milling, including the structural vibration of the tool and workpiece, to calculate the chip thickness at each cutting point. The cutting force of any end milling cutter can be predicted by integrating the machining process of each cutting edge in contact with the workpiece. The model is suitable for spiral cylinder, spiral ball, conical spiral ball, bull head, and special end mill. Gradisek et al. [150] described the external geometry of end mills as a generalized mathematical model, which is applicable to various end milling cutter shapes, such as cylindrical, conical, spherical, and nose shaped. 
Merdol et al. [157] studied the mechanics and dynamics of serrated cylindrical and conical helical end mills using the basic formula type II. The abovementioned researchers have utilized type II to build the model, which considers the size effect, chip thickness, and tool parameters. Later, some researchers have also considered the vibration and cutting parameters. Wang et al. [158] established a dynamic cutting force model for end milling based on type II with consideration of tool geometry, vibration, cutting speed variation, tool chip friction, and other factors. The accuracy of the model is verified by cutting experiments on aluminum alloy Al6061. Desai et al. [159] studied the influence of parametric machining direction and tool diameter on the machining geometry, cutting force, and surface error in cylindrical milling of curved surface geometry. The experimental results of 7075-T6 aluminum alloy are consistent with those of computer simulation. Zaghbani et al. [160] established a new milling force model for dry high-speed end milling of aluminum alloy. The proposed model only needs to know the properties of the material and cutting conditions to estimate the cutting force in the milling process. The model is suitable for the prediction of Al6061-T6 and Al7075-T6 aluminum. Rivière-Lorphèvre et al. [161] improved the recognition algorithm for the effect of radial runout on undeformed chip thickness. Two different types of tool runout tests are conducted on the dynamometer. The simulation results agree well with the experimental results, which can be used to predict the cutting force under different cutting conditions. Matsumura et al. [162] considered that the change in milling force depending on the uncut chip thickness caused by tool runout and proposed a cutting force model considering tool runout. The edge of the end mill is configured according to the runout of the cutter. The cutting test of Al7150 is performed to verify the proposed force model. Some researchers have argued that high spindle speed will lead to the acquisition of cutting forces with high-frequency components. The cutting force signal collected by commercial dynamometer is distorted due to the dynamic characteristics of the workpiece dynamometer at high frequency, which exceeds the bandwidth of the dynamometer. Therefore, the harmonic of cutting force is amplified or attenuated, which leads to inaccurate cutting force signal providing incorrect cutting mechanics and dynamics information. Kiran et al. [163] designed and manufactured 1-DOF and 2-DOF flexible worktable representing the workpiece flexibility to compensate for the abovementioned distortion in the cutting force data. By using the reverse filtering method, the actual cutting force acting on the tool/workpiece is accurately obtained, the accurate measurement of the milling force of the flexible workpiece is realized, and the cutting force model of dry end cutting Al6013-T6 is established.

The cutting coefficients of types I and II represent the quantities related to tool geometry and material properties in the theoretical model, and the simplified micro element cutting force model is called mechanical model. The model is not bound by cutting theory and has strong adaptability. Most existing studies are instantaneous milling force models. The type I micro element milling force model represents the cutting force as a function of the chip section area, where the cutting coefficient is a function of the undeformed chip thickness. In the process of thin-walled workpiece and micro milling, a size effect that changes faster than the milling coefficient exists because the milling thickness is very small. Thus, plough force needs to be considered. Different from type I micro element milling force model, type II micro element milling force model considers the influence of plough shear and shear forces on overall milling force separately and assumes plough shear coefficient as constant. Instantaneous milling force models, whether based on type I or II, are modeled by analyzing the milling thickness model and the milling force coefficient. The instantaneous milling force model is derived as follows.

Using Eqs. (13) and (8) for derivation calculation, $\mathrm{d} S=\mathrm{d} z / \cos \beta$ ( $\beta$ is the spiral angle of tool. $\mathrm{d} S \approx \mathrm{d} z$ for convenient calculation. The end milling cutter is shown in Figures 16 and 17.

Therefore, Eq. (13) can be expressed as

$$
\left\{\begin{array}{l}
\mathrm{d} F_{\mathrm{t}}=K_{t c} h \mathrm{~d} z+K_{t e} \mathrm{~d} z \\
\mathrm{~d} F_{r}=K_{r c} h \mathrm{~d} z+K_{r e} \mathrm{~d} z \\
\mathrm{~d} F_{a}=K_{a c} h \mathrm{~d} z+K_{a e} \mathrm{~d} z
\end{array}\right.
$$

For convenient calculation, micro element cutting force Eq. (14) is converted to rectangular coordinate system, and its conversion relation is expressed as

$$
\left(\begin{array}{l}
\mathrm{d} F_{x, j}(\theta, z) \\
\mathrm{d} F_{y, j}(\theta, z) \\
\mathrm{d} F_{z, j}(\theta, z)
\end{array}\right)=\left(\begin{array}{ccc}
-\cos \theta & -\sin \theta & 0 \\
\sin \theta & -\cos \theta & 0 \\
0 & 0 & 1
\end{array}\right)\left(\begin{array}{l}
\mathrm{d} F_{t} \\
\mathrm{~d} F_{r} \\
\mathrm{~d} F_{a}
\end{array}\right)
$$

Substituting Eq. (15) and Eq. (8) into Eq. (16) yields

$$
\left\{\begin{array}{l}
\mathrm{d} F_{x, j}(\theta, z)=-\left[K_{t c} f_{z} \sin \theta_{j}(z)+K_{t e}\right] \cos \theta_{j}(z) \mathrm{d} z-\left[K_{r c} f_{z} \sin \theta_{j}(z)+K_{r e}\right] \sin \theta_{j}(z) \mathrm{d} z, \\
\mathrm{~d} F_{y, j}(\theta, z)=\left[K_{t c} f_{z} \sin \theta_{j}(z)+K_{t e}\right] \sin \theta_{j}(z) \mathrm{d} z-\left[K_{r c} f_{z} \sin \theta_{j}(z)+K_{r e}\right] \cos \theta_{j}(z) \mathrm{d} z, \\
\mathrm{~d} F_{z, j}(\theta, z)=\left[K_{a c} f_{z} \sin \theta_{j}(z)+K_{a e}\right] \mathrm{d} z .
\end{array}\right.
$$



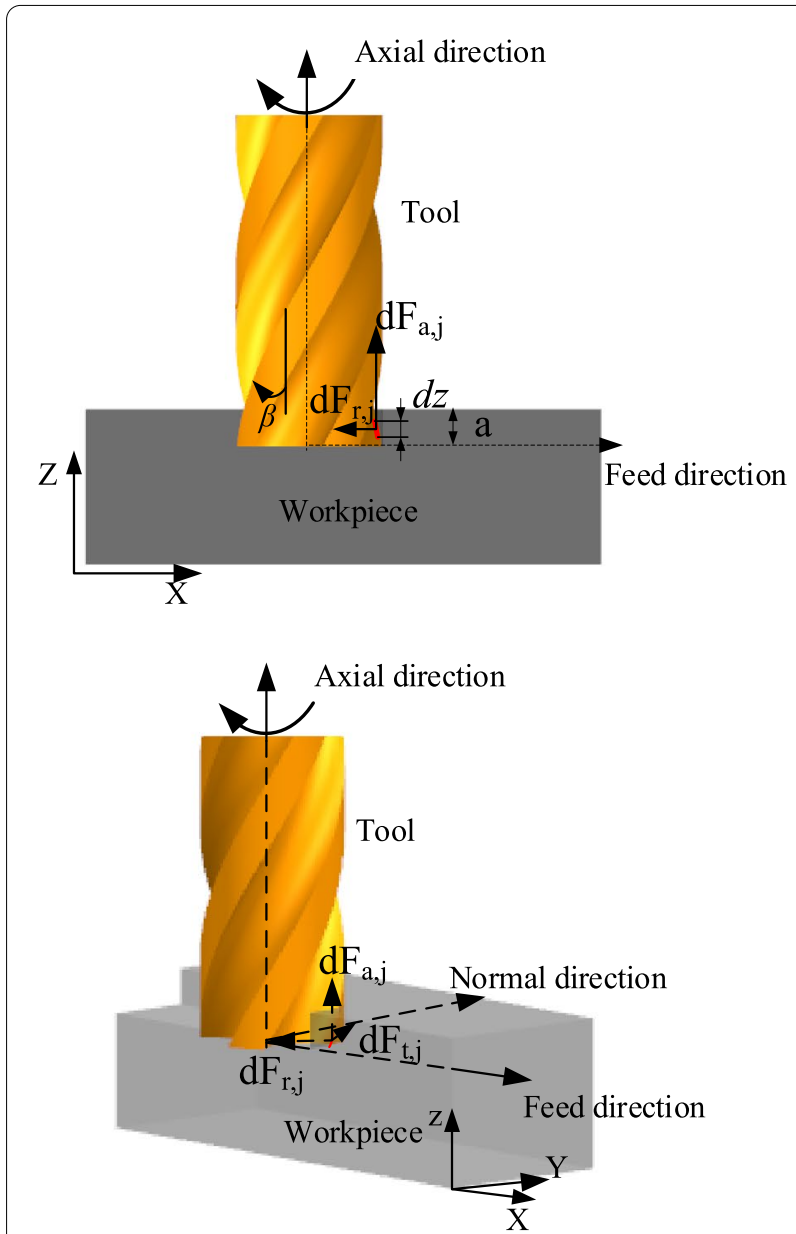

Figure 16 Geometry of cylindrical end-mill

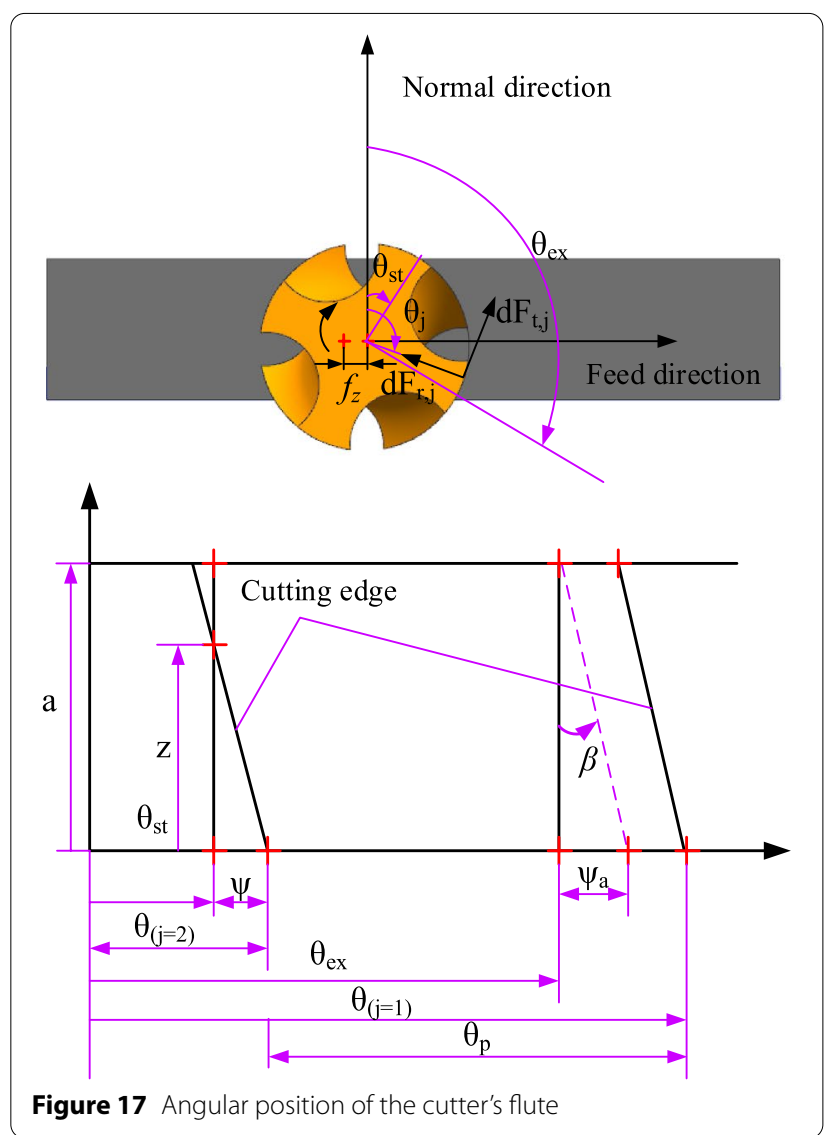

respectively. The change in variable is used as in Eqs. (20) and (21):

$$
\theta_{j}(z)=2 \pi n t-(j-1) \frac{2 \pi}{N}-\frac{2 z \tan \beta}{R} \Rightarrow \mathrm{d} \theta_{j}(\mathrm{z})=-\frac{2 \tan \beta}{R} \mathrm{~d} z .
$$

Eq. (17) is simplified to

$$
\left\{\begin{array}{l}
\mathrm{d} F_{x, j}(\theta, z)=\left\{\frac{f_{z}}{2}\left[-K_{t c} \sin 2 \theta_{j}(z)-K_{r c}\left(1-\cos 2 \theta_{j}(z)\right)\right]+\left[-K_{t e} \cos \theta_{j}(z)-K_{r e} \sin \theta_{j}(z)\right]\right\} \mathrm{d} z, \\
\mathrm{~d} F_{y, j}(\theta, z)=\left\{\frac{f_{z}}{2}\left[K_{t c}\left(1-\cos 2 \theta_{j}(z)\right)-K_{r c} \sin 2 \theta_{j}(z)\right]+\left[K_{t e} \sin \theta_{j}(z)-K_{r e} \cos \theta_{j}(z)\right]\right\} \mathrm{d} z \\
\mathrm{~d} F_{z, j}(\theta, z)=\left[K_{a c} f_{t} \sin \theta_{j}(z)+K_{a e}\right] \mathrm{d} z .
\end{array}\right.
$$

where $\theta_{j}(z)$ is the instantaneous immersion angle of flute number $j$.

In the determination of the total cutting force, the differential cutting forces are integrated analytically along the in-cut portion of the flute $j$, as shown in Eq. (19).

$$
F_{q}\left(\theta_{j}(z)\right)=F_{q}(\theta(z))=\int_{z_{j, 1}}^{z_{j, 2}} \mathrm{~d} F_{q}(\theta, z), q=x, y, z,
$$

where $z_{j, 1}$ and $z_{j, 2}$ are the lower and upper axial engagement limits of the in-cut portion for the flute number $j$,

$$
\mathrm{d} z=-\frac{R}{2 \tan \beta} \mathrm{d} \theta_{j}(z),\left\{\begin{array}{l}
z=z_{j, 1} \rightarrow \theta_{j}(z)=\theta_{j}\left(z_{1}\right) \\
z=z_{j, 2} \rightarrow \theta_{j}(z)=\theta_{j}\left(z_{2}\right)
\end{array}\right.
$$

where $n$ is the spindle speed $(\mathrm{r} / \mathrm{min}), t$ is the milling time (ms), $N$ is the number of teeth in milling cutter, $\beta$ is the spiral angle $\left({ }^{\circ}\right), j$ is the $j$ th spiral edge involved in cutting $(1-N)$, and $R$ is the diameter of cutter $(\mathrm{mm})$.

Substituting Eq. (21) into Eq. (19) yields

$$
F_{q}\left(\theta_{j}(z)\right)=-\frac{R}{2 \tan \beta} \int_{\theta_{j}\left(z_{1}\right)}^{\theta_{j}\left(z_{2}\right)} d F_{q}\left(\theta_{j}(z)\right), q=x, y, z
$$


Substituting Eq. (18) into Eq. (22) yields

$$
\begin{aligned}
& \left\{\begin{array}{l}
F_{x, j}(\theta(z))=-\frac{R}{2 \tan \beta} \int_{\phi_{j}\left(z_{1}\right)}^{\phi_{j}\left(z_{2}\right)}\left\{\frac{f_{z}}{2}\left[-K_{t c} \sin 2 \theta_{j}(z)-K_{r c}\left(1-\cos 2 \theta_{j}(z)\right)\right]+\left[-K_{t e} \cos \theta_{j}(z)-K_{r e} \sin \theta_{j}(z)\right]\right\} \mathrm{d} \theta, \\
F_{y, j}(\theta(z))=-\frac{R}{2 \tan \beta} \int_{\theta_{j}\left(z_{1}\right)}^{\theta_{j}\left(z_{2}\right)}\left\{\frac{f_{z}}{2}\left[K_{t c}\left(1-\cos 2 \theta_{j}(z)\right)-K_{r c} \sin 2 \theta_{j}(z)\right]+\left[K_{t e} \sin \theta_{j}(z)-K_{r e} \cos \theta_{j}(z)\right]\right\} \mathrm{d} \theta \\
F_{z, j}(\theta(z))=-\frac{R}{2 \tan \beta} \int_{\theta_{j}\left(z_{1}\right)}^{\theta_{j}\left(z_{2}\right)}\left[K_{a c} f_{z} \sin \theta_{j}(z)+K_{a e}\right] \mathrm{d} \theta .
\end{array}\right. \\
& \left\{\begin{array}{l}
F_{x, j}(\phi(z))=\left\{-\frac{R f_{z}}{8 \tan \beta}\left[K_{t c} \cos 2 \theta_{j}(z)-K_{r c}\left(2 \theta_{j}(z)-\sin 2 \theta_{j}(z)\right)\right]+\frac{R}{2 \tan \beta}\left[K_{t e} \sin \theta_{j}(z)-K_{r e} \cos \theta_{j}(z)\right]\right\}_{\theta_{j}\left(z_{1}\right)}^{\theta_{j}\left(z_{2}\right)} \\
F_{y, j}(\phi(z))=\left\{-\frac{R f_{z}}{8 \tan \beta}\left[K_{t c}\left(2 \theta_{j}(z)-\sin 2 \theta_{j}(z)\right)-K_{r c} \cos 2 \theta_{j}(z)\right]+\frac{R}{2 \tan \beta}\left[K_{t e} \cos \theta_{j}(z)+K_{r e} \sin \theta_{j}(z)\right]\right\}_{\theta_{j}\left(z_{1}\right)}^{\theta_{j}\left(z_{2}\right)},(2 \\
F_{z, j}(\theta(z))=\left\{\frac{R f_{t}}{2 \tan \beta}\left[K_{a c} \cos \theta_{j}(z)+\frac{R}{2 \tan \beta} K_{a e} \theta_{j}(z)\right]\right\}_{\theta_{j}\left(z_{1}\right)}^{\theta_{j}\left(z_{2}\right)}
\end{array}\right.
\end{aligned}
$$

The lag angle at full axial depth of cut is calculated by Eq. (25):

$$
\psi_{\mathrm{a}}=\frac{2 \tan \beta}{R} a,
$$

where $\psi_{\mathrm{a}}$ is the lag angle at maximum axial depth of cut $z=a\left({ }^{\circ}\right)$.

The milling forces exist only when the cutting tool is in the cutting zone, as shown in Figure 18, and can be expressed in Eq. (26):

$$
\theta_{\mathrm{st}} \leq \theta_{j} \leq \theta_{\mathrm{ex}}+\psi_{\mathrm{a}},
$$

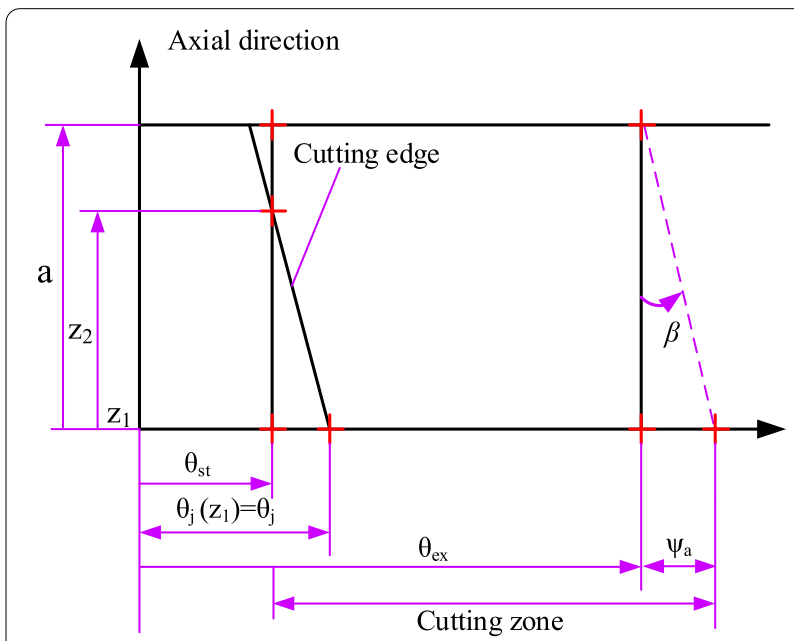

Figure 18 Boundary conditions

$$
\begin{gathered}
\left\{\begin{array}{c}
\theta_{\mathrm{st}}=\pi-\arccos \frac{R-a_{e}}{R} \\
\theta_{\mathrm{ex}}=\pi
\end{array} \Rightarrow\right. \text { for down milling, } \\
\left\{\begin{array}{c}
\theta_{\mathrm{st}}=\pi \\
\theta_{\mathrm{ex}}=\pi-\arccos \frac{R-a_{e}}{R}
\end{array} \Rightarrow\right. \text { for up milling, }
\end{gathered}
$$

where $\theta_{\text {st }}$ is the cutter entry angle $\left(^{\circ}\right), \theta_{j}$ is the instantaneous immersion angle of flute number $j\left(^{\circ}\right), \theta_{\mathrm{ex}}$ is the cutter exit angle $\left({ }^{\circ}\right)$, and ae is working engagement of the cutting edge $(\mathrm{mm})$.

In each revolution, the boundary conditions for calculation of milling forces are illustrated as in Figure 19 and can be expressed in Eq. (29):

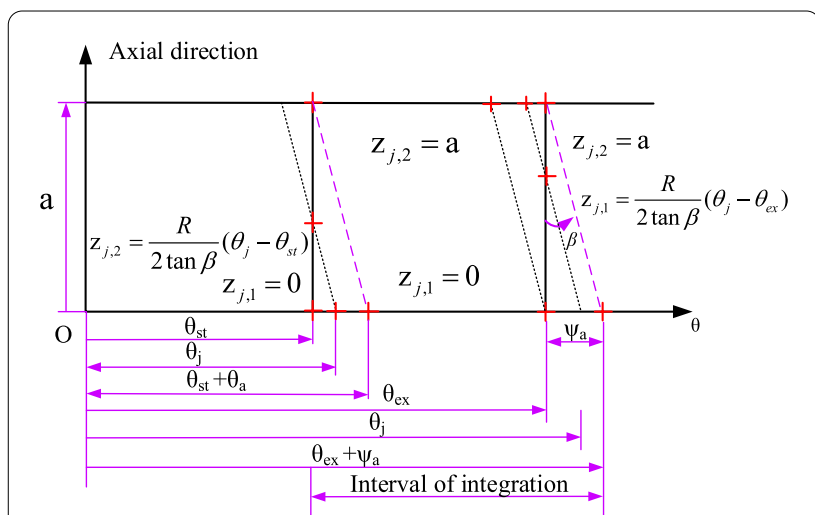

Figure 19 Integral interval 


$$
\left\{\begin{array}{l}
\text { If }\left(\theta_{j}<\theta_{\mathrm{st}}\right) \text { or }\left(\theta_{j}>\theta_{\mathrm{ex}}+\psi_{\mathrm{a}}\right) \Rightarrow \text { Out of cut: } F_{(x, y, z)}(j)=0, \\
\text { If }\left(\theta_{\mathrm{st}}<\theta_{j}<\theta_{\mathrm{st}}+\psi_{\mathrm{a}}\right) \Rightarrow \text { cutting }\left\{\begin{array}{l}
\theta_{j}\left(z_{1}\right)=\theta_{\mathrm{st}}, \\
\theta_{j}\left(z_{2}\right)=\theta_{j},
\end{array}\right. \\
\text { If }\left(\theta_{\mathrm{st}}+\psi_{\mathrm{a}}<\theta_{j}<\theta_{\mathrm{ex}}\right) \Rightarrow \text { cutting }\left\{\begin{array}{l}
\theta_{j}\left(z_{1}\right)=\theta_{j}-\psi_{\mathrm{a}}, \\
\theta_{j}\left(z_{2}\right)=\theta_{j},
\end{array}\right. \\
\text { If }\left(\theta_{\mathrm{ex}}<\theta_{j}<\theta_{\mathrm{ex}}+\psi_{\mathrm{a}}\right) \Rightarrow \text { cutting }\left\{\begin{array}{l}
\theta_{j}\left(z_{1}\right)=\theta_{j}-\psi_{\mathrm{a}}, \\
\theta_{j}\left(z_{2}\right)=\theta_{\mathrm{ex}} .
\end{array}\right.
\end{array}\right.
$$

By using Eq. (30), the predicted value of each direction milling force can be summarized, and the real-time milling force during machining can be simulated:

$$
F_{x}=\sum_{j=1}^{N} F_{x, j}\left(\theta_{j}\right), F_{y}=\sum_{j=1}^{N} F_{y, j}\left(\theta_{j}\right), F_{z}=\sum_{j=1}^{N} F_{z, j}\left(\theta_{j}\right) .
$$

\subsection{Milling Force Coefficient}

The accuracy of milling force prediction largely depends on the milling force coefficient of materials. The recognition of milling force coefficient is the core of milling force model. In the analytical model of milling force, the cutting force coefficient is the most significant parameter and must be determined. The milling force coefficient represents the milling force per unit area in the cutting process, and it is affected by the geometric parameters of the cutter, the material properties of the tool and workpiece, and the cutting thickness [164]. In using the tool discrete model and analytical method to solve the instantaneous milling force, the prediction accuracy of milling force largely depends on the cutting force coefficient; thus, the cutting force coefficient plays an important role in the accurate prediction of milling force $[78,150,165$, 166].

According to the different identification bases of cutting force coefficient, the commonly used identification methods can be divided into three types: analytical calculation method, identification method based on measured milling force, and identification method based on surface error.

\subsubsection{Analytical Calculation Method}

The method is based on Oxley cutting prediction theory and Merchant cutting theory, and the shear slip theory is applied. The cutting force coefficient of oblique cutting is calculated according to different tool geometry models with the tool-chip area and shear zone as the research objects. The analytical model of milling force coefficient can be expressed as a function of shear angle $\phi_{c}$, average friction angle $\beta_{a}$, shear yield strength $\tau_{s}$, tool rake angle $\alpha_{r}$, tool helix angle $\beta$, and chip flow angle $\eta$ [167]:

$$
\left\{\begin{array}{l}
K_{t c}=\frac{\tau_{s}}{\sin \phi_{c}} \times \frac{\cos \left(\beta_{a}-a_{r}\right)+\tan (\beta) \tan (\eta) \sin \left(\beta_{a}\right)}{\sqrt{\cos ^{2}\left(\phi_{c}+\beta_{a}-\alpha_{r}\right)+\tan ^{2}(\beta) \sin ^{2}\left(\beta_{a}\right)}}, \\
K_{r c}=\frac{\tau_{s}}{\cos \phi_{c} \cos (\beta)} \times \frac{\sin \left(\beta_{a}-\alpha_{r}\right)}{\sqrt{\cos ^{2}\left(\phi_{c}+\beta_{a}-\alpha_{r}\right)+\tan ^{2}(\beta) \sin ^{2}\left(\beta_{a}\right)}}, \\
K_{a c}=\frac{\tau_{s}}{\sin \phi_{c}} \times \frac{\cos \left(\beta_{a}-a_{r}\right) \tan (\beta)-\tan (\eta) \sin \left(\beta_{a}\right)}{\sqrt{\cos ^{2}\left(\phi_{c}+\beta_{a}-\alpha_{r}\right)+\tan ^{2}(\beta) \sin ^{2}\left(\beta_{a}\right)}} .
\end{array}\right.
$$

Lee et al. [168] argued that the milling force is not only related to the chip geometry but also closely related to the arc length of the cutting micro element. Merdol et al. [157] used the die to determine the coefficients of the force model for milling aviation aluminum alloy 7050T7451 with serrated cylinder and conical spiral end mills.

\subsubsection{Identification Method Based on Measured Milling Force}

This method is commonly used to identify the cutting force coefficient by using the measured milling force. This method can be divided into two categories. One is to use the cutting force coefficient as a function of constant or average cutting thickness, which is called the average cutting force coefficient [121,125,127,169-173]. The other is that each cutting element has a different cutting force coefficient, which is called instantaneous cutting force coefficient [126, 146, 165, 174, 175].

Gradisek and Yoon et al. [50, 150] adopted constant milling force coefficient and changed feed per tooth while keeping other milling parameters unchanged. Linear relationship between average milling force and feed rate per tooth is obtained through linear regression analysis to separate shear and plough force, and obtain shear and plough effect coefficients. Kang and Yin et al. [176-178] used the average milling force to calculate the cutting force coefficient in the centralized cutting force model. They also established the quadratic polynomial relationship between the milling force coefficient and spindle speed, feed rate, and radial and axial cutting depth through orthogonal test method and regression analysis. Campatelli et al. [179] established an appropriate mathematical model to describe the response characteristics to explore the relationship between milling force coefficient and cutting speed and feed per tooth. Liu et al. [180] studied the variation in cutting force coefficient with axial depth, radial width, and feed rate. The modified cutting force coefficient is obtained by average milling force method. Yu et al. [181] studied the relationship between cutting force coefficient and spindle speed and axial cutting depth. The results show that spindle speed slightly affects milling force coefficient, while axial cutting depth greatly influences milling force coefficient. Liu [182] established the multiple quadratic regression equation of milling force coefficient by response surface method, studied the influence of feed rate per tooth, spindle speed and cutting depth on cutting coefficient, and established the local milling force model under 
different combinations of process parameters. Previous researchers have mainly studied the individual cutting parameters but have ignored the geometric parameters of the tool. Kao et al. [183] proposed a cutting force coefficient estimation method based on stable milling conditions. The cutting force coefficient model is composed of a function of the average cutting force and the geometric parameters of the tool (e.g., tool diameter, number of slots, and tool helix angle). On this basis, Adam et al. [184] extracted the cutting force coefficient of aluminum alloy al6061-t6511 by average force and optimization technology methods. Tsai et al. [185] studied the effects of feed rate per tooth and tool diameter on cutting force and cutting coefficient. On this basis, the cutting parameters, including friction angle and shear stress, are estimated using oblique cutting theory. Ozturk et al. [186] analyzed the influence of spiral angle on milling force coefficient by conducting Al7075 milling experiments on five kinds of cutting tools with different spiral angles. For ball end milling cutter milling surface, Tukora et al. [187] introduced an algorithm for determining the milling force coefficient of single test without cutting geometry constraints. They also performed detailed analysis and verification for ball end milling of aluminum alloy AlMgSi1. The abovementioned works have mainly studied the relationship between milling force coefficient and milling parameters. Meanwhile, Wang et al. [164] verified that milling force coefficient is only related to tool workpiece material coupling and cutter geometric parameters and is not affected by milling parameters through groove milling experiment. Bai [188] expressed the cutting force coefficient as an exponential function of the average cutting thickness.

The average milling force is used to identify the cutting coefficient in the abovementioned literature, as shown in Table 5. Although the forms of milling force coefficients slightly differ, several milling experiments are needed. Most scholars have believed that the milling force coefficient is mainly related to milling parameters, while a few researchers have argued that the milling force coefficient is only related to the geometric parameters of the cutter and is not affected by the milling parameters. The researchers of average cutting force coefficient all believed that the cutting force coefficient is a fixed value under a certain fixed working condition while the change in cutting thickness in some positions is ignored.

Some scholars have proposed the concept of instantaneous cutting force coefficient and comprehensively studied its identification method to improve the prediction accuracy of instantaneous cutting force and reduce the amount of experiments [92, 152, 165, 166, 191, 192]. Shin et al. [192] proposed a new method to determine the instantaneous cutting force coefficient required for process simulation through mechanical modeling. This method considers the size effect, greatly reduces the number of calibration experiments, and improves the accuracy of dynamic cutting force and force signal. Cheng et al. [165] studied the characteristics of instantaneous cutting force coefficient of face milling cutter. The results show that the normal force coefficient is mainly affected by the chip thickness and cutting speed, the vertical force coefficient is mainly affected by the chip thickness, cutting edge length, and cutting speed, and the horizontal force coefficient is affected by the chip thickness cutting speed, and cutting length. Yun et al.

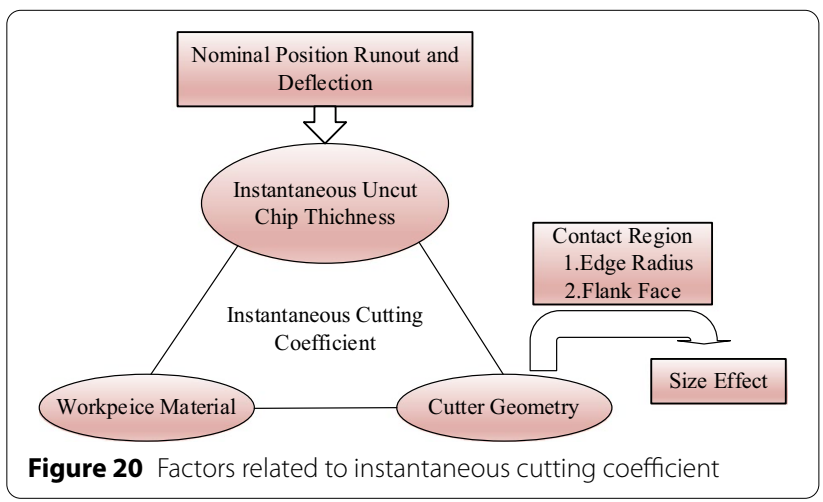

Table 5 Model coefficients of milling force for aerospace aluminum alloy

\begin{tabular}{|c|c|c|c|c|c|c|c|c|c|}
\hline Ref. & Cutter material & Lubrication & Workpiece & $K_{t c}\left(\mathrm{~N} / \mathrm{mm}^{2}\right)$ & $K_{t e}(\mathrm{~N} \cdot \mathrm{mm})$ & $K_{r c}\left(\mathrm{~N} / \mathrm{mm}^{2}\right)$ & $K_{r e}(\mathrm{~N} \cdot \mathrm{mm})$ & $K_{a c}\left(\mathrm{~N} / \mathrm{mm}^{2}\right)$ & $K_{a e}(\mathrm{~N} \cdot \mathrm{mm})$ \\
\hline [189] & Cemented carbide & Dry & Al6082-T6 & 631 & 13 & 99 & 10 & 273 & 2.8 \\
\hline$[190]$ & Cemented carbide & Dry & Al7075-T6 & 767.01 & 27.7 & 168.8 & 26.6 & 222 & 0.7 \\
\hline$[160]$ & Cemented carbide & Dry & Al6061-T6 & 243.77 & 7.53 & 113.5 & 7.83 & - & - \\
\hline$[160]$ & Cemented carbide & Dry & Al7075-T6 & 600.46 & 17.9 & 180.96 & 20.42 & - & - \\
\hline$[150]$ & Cemented carbide & $\mathrm{mql}$ & AlMgSi0.5 & 561.2 & 204.3 & 194.4 & 16.2 & 6.7 & 2.2 \\
\hline$[157]$ & Cemented carbide & Dry & Al7050-T7451 & - & 23.4 & - & 35.16 & - & 0 \\
\hline$[156]$ & High-speed steel & Dry & Al7075 & 951.365 & 11.115 & 262.597 & 11.314 & 323.33 & 1.105 \\
\hline [47] & Cemented carbide & Dry & Al7075 & 1319.41 & 19.65 & 788.83 & 26.77 & 48.75 & 2.05 \\
\hline
\end{tabular}


[116] believed that the cutting force coefficient is only affected by the thickness of uncut chips. The instantaneous unchipped thickness is estimated by tracking the movement of tool center position, and the cutting force coefficient is determined by the unchipped thickness. The abovementioned researchers have mainly considered the size effect into the instantaneous cutting thickness and then studied the relationship between the instantaneous cutting force coefficient and the cutting thickness while the error caused by the tool deflection and the running out is ignored. Ko et al. [174] calculated the relationship between instantaneous uncut thickness and cutting coefficient by tracking the changes in tool center position with feed rate, tool deflection, and runout. Thereafter, Ko et al. [175] proposed a method to estimate the instantaneous cutting force coefficient of ball end milling cutter. According to the relationship between instantaneous uncut chip thickness and instantaneous cutting force, the instantaneous cutting force coefficient is derived using the cutting force model considering deflection and runout. The factors related to the instantaneous milling force coefficient are shown in Figure 20.

Wan et al. [191] proposed three calibration methods for instantaneous cutting force coefficient and tool runout parameter in cylindrical milling and analyzed and verified the different parameters of instantaneous milling force coefficient model. Then, Wan et al. [193] expressed the instantaneous milling force coefficient as an exponential function of instantaneous uncut chip thickness. Ning et al. [194] described the milling force coefficient as a power function of instantaneous undeformed chip thickness. The model can be used to predict the cutting force of aviation aluminum alloy 6061, and the accuracy of the prediction model is between $3 \%$ and $10 \%$. The research on instantaneous cutting force coefficient has mainly

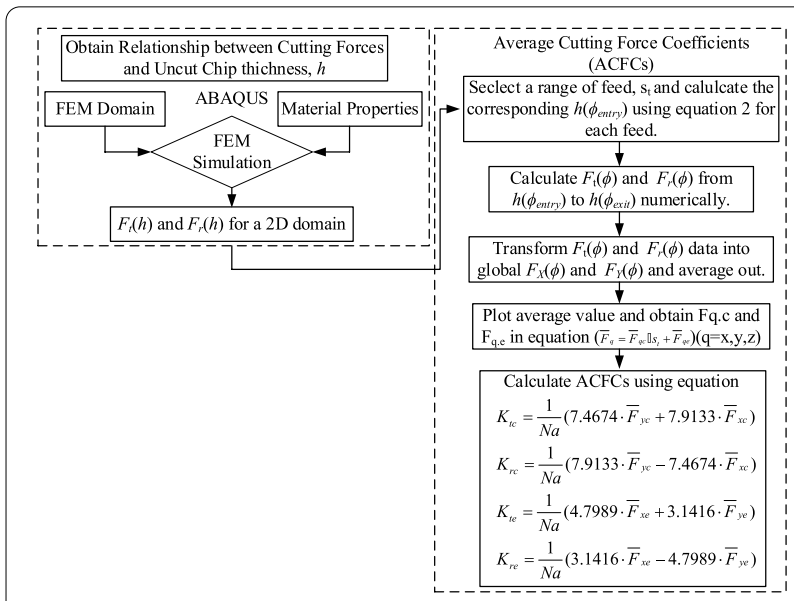

Figure 21 Steps for estimating average cutting force coefficients focused on the relationship between instantaneous cutting force coefficient and cutting thickness and then considered the error caused by size effect, tool deflection, and runout to improve the accuracy of instantaneous cutting force to a certain extent. Average and instantaneous cutting force coefficients need a certain number of experiments to provide data support, and some even require several orthogonal experiments.

Adetoro et al. [51] introduced an efficient and accurate numerical tool for simulation of cutting process and determination of average and instantaneous milling force coefficients, as shown in Figure 21. The main advantage of this method over other available methods is that no experimental calibration is needed. The milling force coefficient is obtained by the least square method, and the milling force is predicted by the evaluation coefficient. The results agree well with the experimental results, and the accuracy is satisfactory.

This kind of simulation provides data support regardless whether the simulation is conducted in the ideal machining environment. However, the measured cutting force will change to a certain extent in the actual cutting process due to tool wear, deflection, and runout.

\subsubsection{Identification Method Based on Surface Error}

In the process of milling, the bending deformation of tool and workpiece will occur under the action of milling force and will be recorded on the workpiece surface, which also provides another possible way to identify the cutting force coefficient.

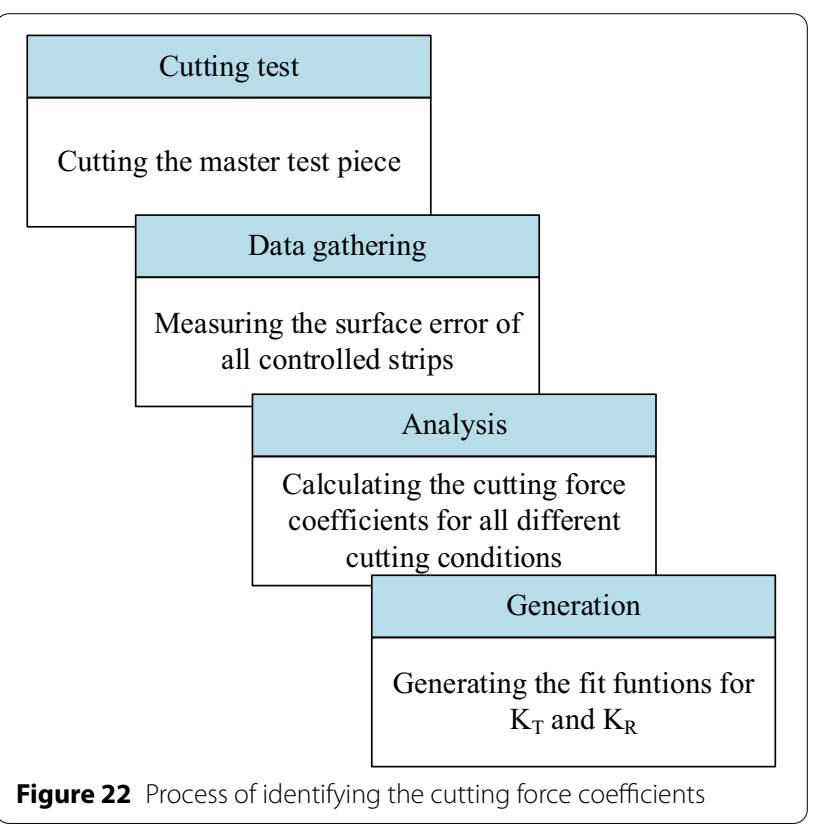


Tsai et al. [195] used the surface error of thin-walled workpiece to provide the identification method of milling force coefficient. Kim and Xu [196, 197] identified the cutting force coefficient according to the surface error of "slender" tool when machining workpiece. As shown in Figure 22, Dotcheva et al. [198] believed that tool deviation caused by milling force is the main factor of surface error. Under the same cutting conditions, the two aluminum alloy 6082 metal plates are cut. The axial cutting depth varies with the height of the metal plate. Therefore, the resulting surface error represents the deviation of the cutter when the cutting axial depth is equal to the strip of the cutter's basic axial disk. The size effect is considered when generating a function of the cutting force coefficient. This method overcomes the problem of analyzing and calculating the relationship between the measured value of milling force and the instantaneous chip thickness in the process of determining the traditional cutting force coefficient. The new method provides the instantaneous cutting force coefficient that is independent of the cutting operation geometry for the simulation process. The calculated results of the new cutting force coefficient agree well with the measured surface errors. However, the feedback of tool deformation on milling force is ignored.
All the abovementioned studies have assumed that the surface error of the workpiece is mainly caused by the deformation of the workpiece and the tool. In this method, the surface error caused by other factors can be nearly ignored compared with the deformation of the workpiece and the tool during the thin-walled workpiece processing. The cutting force coefficient can also be accurately identified. However, the surface error caused by neglecting the accuracy of machine tool in machining non-thin-walled parts greatly affects the accuracy of identification, which is also the reason why the method has not been used in practice.

Table 6 shows the research on milling force coefficient. From the abovementioned analysis, the milling edge of the milling tool in the analytic method is more complex in practical application, using the formula of the analytical calculation method is more cumbersome, and the results have large deviation from the actual situation.

The measured milling force is a commonly used method to identify the milling force coefficient and has attracted the attention of many scholars. As mentioned earlier, several milling experiments are required although the expression forms of milling force coefficient slightly differ. The milling force coefficient is assumed to be a function of the average chip thickness and is determined using the measured average force data. In these

Table 6 Literature on milling force coefficient

\begin{tabular}{|c|c|c|c|c|}
\hline \multirow[t]{2}{*}{ Year } & \multirow[t]{2}{*}{ Analytical method } & \multicolumn{2}{|c|}{ Identification method based on actual milling force } & \multirow{2}{*}{$\begin{array}{l}\text { Workpiece surface error } \\
\text { identification method }\end{array}$} \\
\hline & & Average cutting force coefficient & Instantaneous cutting force coefficient & \\
\hline 1985 & Tool parameters [167] & & & \\
\hline 1995 & Tool parameters [168] & & Helix angle [183] & \\
\hline 1997 & & & Cutting force signals [165] & \\
\hline 1999 & & & & Cutting system deflections [195] \\
\hline 2001 & & & Chip flow angle [116] & \\
\hline 2002 & & & $\begin{array}{l}\text { Feed; cutter deflection; cutter runout. } \\
{[174]}\end{array}$ & \\
\hline 2003 & Tool parameters [157] & Tool parameters [150] & & Cutter flexibility $[196,197]$ \\
\hline 2004 & & & Deflection; runout [175] & \\
\hline 2007 & & Cutting depth $[176,177]$ & & Cutter deflection [198] \\
\hline 2008 & & Milling parameters $[188,199]$ & Cutter runout [191] & \\
\hline 2009 & Tool parameters [178] & & ALE formulation Cutter runout $[51,154]$ & \\
\hline 2011 & & Cutting geometry [187] & & \\
\hline 2012 & & Feed per tooth and cutting speed [179] & & \\
\hline 2014 & & Milling parameters $[164,183]$ & Chip thickness [194] & \\
\hline 2015 & & Optimization technique $[184,185]$ & & \\
\hline 2016 & & Material data [200] & & \\
\hline 2018 & & $\begin{array}{l}\text { Axial depth; radial width; feed rate [180, } \\
181,201]\end{array}$ & & \\
\hline 2020 & & $\begin{array}{l}\text { Feed per tooth; spindle speed; cutting } \\
\text { depth [182] }\end{array}$ & & \\
\hline
\end{tabular}


models, accurately predicting the chip force component at the peak or valley position is difficult because of the great difference between the average and instantaneous chip thicknesses. When the instantaneous cutting force coefficient is expressed as an exponential function of the instantaneous cutting thickness, the prediction accuracy of the instantaneous milling force can be improved and the experimental amount of the identification of the cutting coefficient can be reduced. If a large error exists in the measurement of the instantaneous milling force or the calculation error of the instantaneous milling thickness, then obtaining a reliable milling force coefficient is difficult, especially near the cutting position of the cutter. The size effect of the milling force coefficient is more prominent because the instantaneous milling force and the instantaneous cutting thickness are very small. In thin-walled workpiece or micro milling process, the identification method of cutting force coefficient is indicated using the surface error of thin-walled workpiece processing. The surface error caused by other factors in thin-walled workpiece processing can be ignored compared with the deformation of the workpiece and cutter, and the cutting force coefficient can be identified more accurately.

\section{Discussion}

\subsection{Summary and Existing Problems}

Aeronautical aluminum alloy is widely used in automobile industry, aviation industry, precision instrument, and machinery industry because of its low density, light weight, good corrosion resistance, and excellent comprehensive performance. However, this material easily deforms under the action of cutting force because of its poor structural rigidity, and this deformation results in poor machining accuracy and surface quality. Therefore, this study analyzes the current situation of aviation aluminum alloy milling force model. According to the analysis of the abovementioned milling force modeling method, the empirical model mainly considers the influence of cutting parameters, such as cutting speed, feed per tooth, axial cutting depth, and radial cutting depth on milling force. Then, this model obtains the final empirical formula through Taguchi orthogonal experiment. The model needs several experiments to collect a large number of experimental data, which cannot reflect the changing law of cutting force with tool movement in the cutting process, as shown in Figure 23. The empirical model ignores the analysis of complex metal cutting theory, material shear, and friction in the milling process. The establishment of an empirical model for predicting milling force must rely on several milling experiments, and the accuracy of the prediction value depends on the number of coefficients, exponents, and experiments in the model. Figure 24 shows the analysis structure of milling force model.

Application of empirical model:

(1) The relationship between milling parameters and milling force is described without considering the material removal mechanism.

(2) The process of establishing the empirical model for predicting the milling force of end mills is simple and pertinence, which is suitable for the parameter optimization in the actual mass production process.

(3) The milling force predicted by the empirical model ignores the errors caused by tool runout, tool eccentricity runout, and size effect. Thus, it is unsuitable for thin-walled workpiece milling and micro milling.

Compared with other methods, the finite element simulation technology can effectively save time and

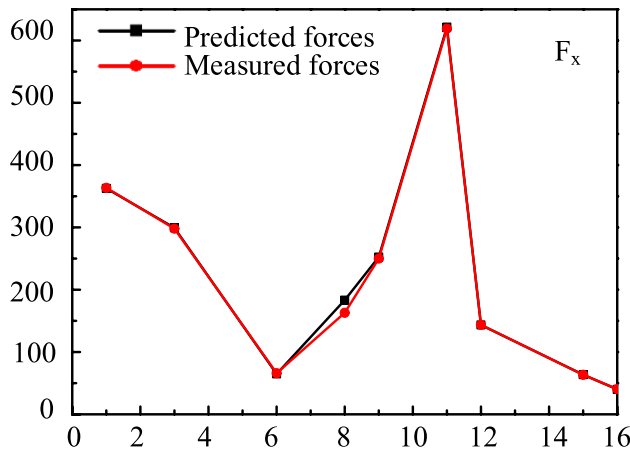

(a) Empirical model

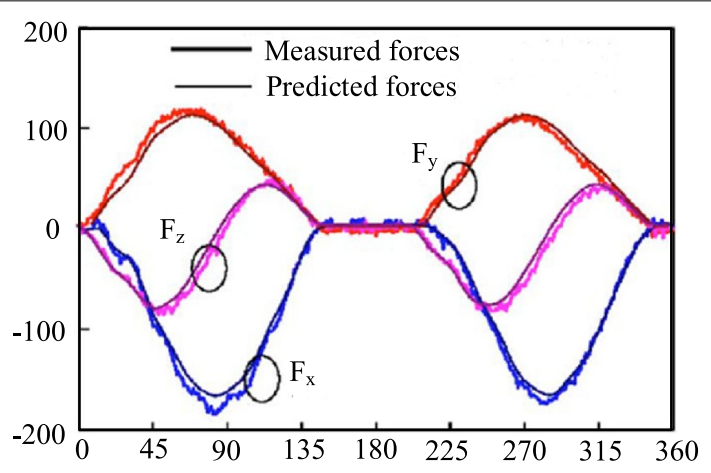

(b) Instantaneous milling force model

Figure 23 The predictive data forms of empirical model and instantaneous milling force model $[68,148]$ 


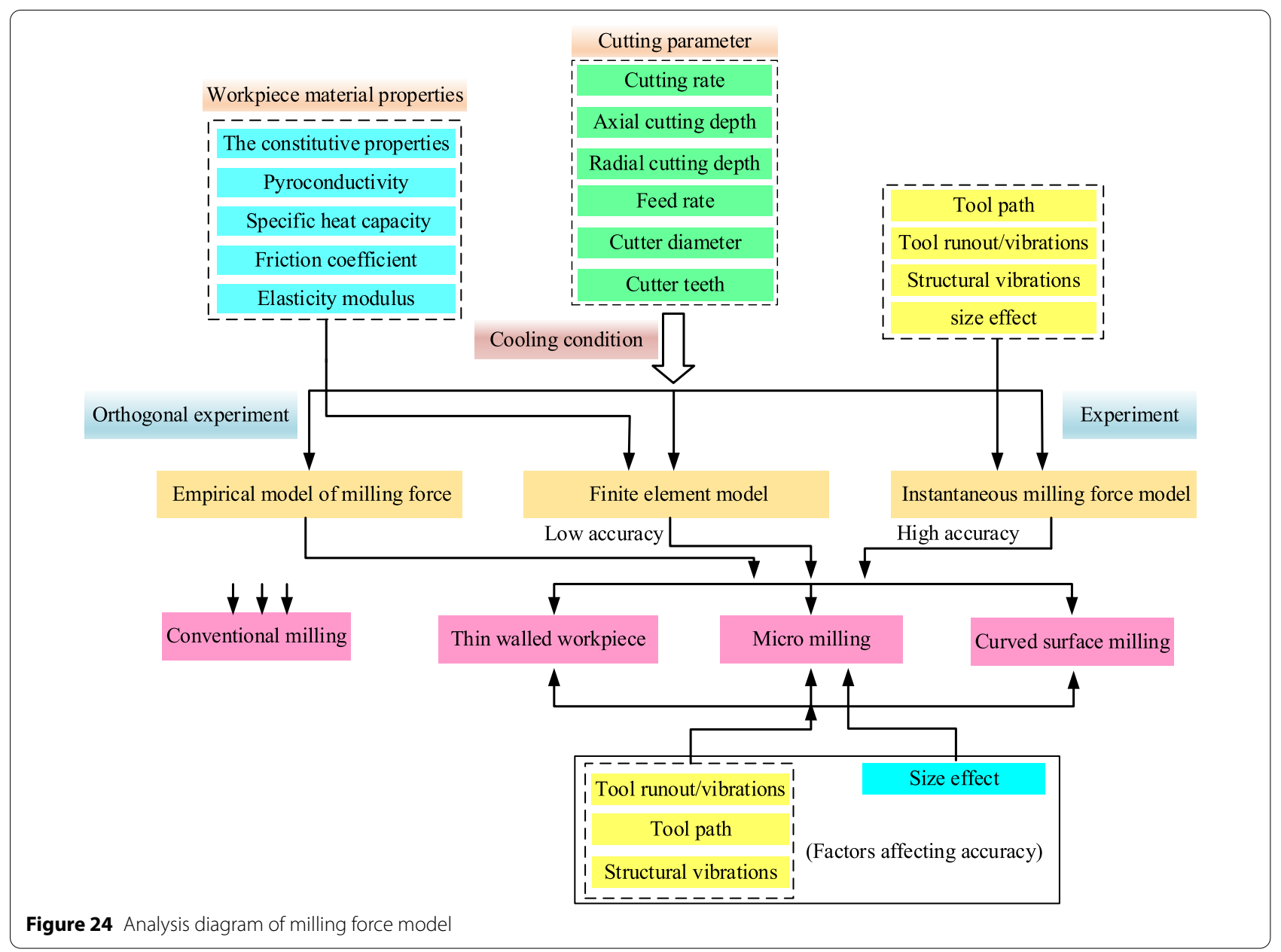

reduce the number of repeated tests and the processing cost. It has the advantages that traditional analytical and experimental methods have difficulty achieving. The finite element prediction model uses the constitutive equation to express the properties of the materials used. The bond and sliding models are used to simulate the relative motion between the chip and the tool, which can form the nonlinear boundary conditions on the chip surface. Apart from cutting force and chip geometry, stress distribution and temperature distribution can also be obtained. However, some inherent errors exist in the measurement system. Finite element model simulation must be performed with the help of simulation software. For example, the mainstream finite element software for cutting simulation includes Abaqus/Explicit, Deform, AdvantEdge, Ansys/LS-DYNA, and Marc.

Application of finite element model:

(1) In finite element simulation, the tool is a rigid body with absolute sharpness. In practice, the tool will wear out. Thus, ignoring the tool wear is reasonable.

(2) During the actual machining, the machine tool will vibrate, and the tool will vibrate due to the "dynamic balance effect." However, the finite element simulation is completely conducted under the ideal situation.

The instantaneous milling force model is based on the mechanical research of cutting process. Considering that the cutting process is a comprehensive system involving multiple inputs and multiple outputs, a comprehensive cutting model for various cutting conditions is established to reveal the cutting process, predict the effective output parameters, and express the relationship between the input and output of the system. For thin-walled workpiece milling, micro milling, and surface milling, the machining accuracy is required to be high. Tool runout, tool and workpiece deformation, tool tip cycloid trajectory, and size effect should be considered. The milling thickness model and milling force coefficient 
of instantaneous milling force model can consider these factors.

Application of instantaneous milling force model:

(1) Type I micro element milling force model is suitable for conventional milling, while type II micro element milling force model is needed for thin-walled workpiece milling and micro milling.

(2) The instantaneous milling thickness is established according to the feed rate of each tooth and the position of micro element. However, for micro milling, the eccentric runout of cutter, deformation of tool and workpiece, and size effect should be considered; for surface milling, the analytical model of milling thickness is established mainly according to the real tooth profile trajectory and the geometric characteristics of the machined surface. However, the milling parameters, such as inclination angle, lead angle, feed per tooth, cutting depth, cutting speed, and tool runout, are also affecting factors of the accuracy of milling thickness model.

(3) In thin-walled workpiece or micro milling, the identification method of milling force coefficient is given using the surface error of thin-walled workpiece, which can accurately identify the cutting force coefficient. However, the surface error caused by neglecting the accuracy of the machine tool greatly affects the accuracy of the identification. This method is commonly used to identify the cutting force coefficient by using the measured milling force. The instantaneous cutting force coefficient is expressed as an exponential function of the instantaneous cutting thickness, which can improve the prediction accuracy of the instantaneous milling force.

\subsection{Future Work}

In view of the existing problems, this study puts forward the following aspects of research on milling force model:

High-speed milling is adopted for the thin-walled structure of large aviation with large cutting depth, and this method easily produces high residual stress on the workpiece surface. Milling force is an important affecting factor of the distribution of residual stress in milling process. The residual stress should be analyzed under this particular condition.

In the process of establishing the instantaneous milling force model, most researchers have mainly focused on one or two factors, and milling force is the result of multiparameter coupling, especially for micro milling and complex surface machining. The modeling of milling force should comprehensively consider multiple factors (e.g., milling parameters, lubrication conditions, tool eccentric runout, tool and workpiece deformation, and size effect).

Different numerical, analytical and experimental methods have been applied. However, the database needs further development to include new workpiece materials, tools (geometries and coatings), working condition, and uncertainty quantification for increasing its utility.

The stiffness of thin-walled parts is very low. Thus, workpiece chatter easily occurs in the final finishing process, which is an affecting factor of the machining quality of thin-walled workpiece. However, the chatter of cutting tool and workpiece in the process of machining has been ignored in the current research to simplify the milling force model. This negligence affects the accuracy of milling force to a certain extent.

$\mathrm{mql}$ and nmql are resource-saving and environmentfriendly cooling lubrication methods and are therefore widely used in milling. However, most force models are established under dry or flood lubrication conditions, but few are under mql. Therefore, the prediction of milling force under $\mathrm{mql}$ and $\mathrm{nmql}$ should be further studied.

\section{Conclusions}

This paper reviews the research progress of cutting force models in the traditional end face milling, thin-walled workpiece milling, micro milling, and curved surface milling of aerospace aluminum alloy. The research progress of cutting force model is reviewed from three modeling methods: empirical model, finite element simulation, and instantaneous milling force model. This paper reviews the relevant papers and summarizes each part in detail. The problems of cutting force modeling are also determined. In view of these problems, the future work direction is proposed mainly in the following four aspects: (1) high-speed milling is adopted for the thinwalled structure of large aviation with large cutting depth, and it easily produces high residual stress. Milling force is an important affecting factor of the distribution of residual stress. The residual stress should be analyzed under this particular condition. (2) Multiple factors (e.g., eccentric swing milling parameters, lubrication conditions, tools, tool and workpiece deformation, and size effect) should be considered comprehensively when modeling instantaneous milling forces, especially for micro milling and complex surface machining. (3) The database of milling force model, including the corresponding workpiece materials, cutting tools (geometric figures and coatings), 
and other parameters, should be established. (4) In thinwalled workpiece milling, the effect of chatter on the prediction accuracy of milling force cannot be ignored. (5) The prediction of mql and nmql milling forces should be further analyzed.

\section{Acknowledgements \\ Not applicable.}

\section{Authors' Contributions}

$\mathrm{CL}$ was in charge of the whole trial. ZD wrote the manuscript. YZ, MY, and TG gave some suggestions on the arrangement of the structure diagram and table in the paper. They also sorted out the relevant references. WD, XX, DW, and CM put forward some suggestions on the thinking of the paper. GMK, MJ, and HMA read and approved the final manuscript, especially the abstract. All authors read and approved the final manuscript.

\section{Authors' Information}

Zhenjing Duan, a postgraduate student at School of Mechanical and Automotive Engineering, Qingdao University of Technology, China. His main research interests is green milling technology.

Changhe Li, a professor at School of Mechanical and Automotive Engineering, Qingdao University of Technology, China. He received his Ph.D. degree from Northeastern University, China. His main research interests include precision and sustainable manufacturing.

Wenfeng Ding, a professor at College of Mechanical and Electrical Engineering, Nanjing University of Aeronautics and Astronautics, China. He received his Ph.D. degree from Nanjing University of Aeronautics and Astronautics, China. His main research interests include machining process simulation and control technology.

Yanbin Zhang, a professor at School of Mechanical and Automotive Engineering, Qingdao University of Technology, China. He received his Ph.D. degree from Qingdao University of Technology, China. His main research interests include grinding and sustainable cutting.

Min Yang, an associate professor at School of Mechanical and Automotive Engineering, Qingdao University of Technology, China. She received Ph.D. degree from Qingdao University of Technology, China. Her main research interests include sustainable cutting and biomaterial grinding.

Teng Gao, a Ph.D. candidate at School of Mechanical and Automotive Engineering, Qingdao University of Technology, China. He received master degree from Qing dao University of Technology, China. His main research interests include grinding and sustainable cutting.

Huajun Cao, a professor at State Key Laboratory Mechanical Transmission, Chongqing University, China. He received Ph.D. degree from Chongqing University, China. His main research interests include advanced manufacturing technology, green manufacturing and equipment, and manufacturing systems engineering.

Xuefeng Xu, a professor at Key Laboratory of Special Purpose Equipment and Advanced Processing Technology, Ministry of Education \& Zhejiang Province, Zhejiang University of Technology, China. He received Ph.D. degree from Zhejiang University of Technology, China. His main research interests include precision and special processing technology.

Dazhong Wang, a professor at School of Mechanical and Automotive Engineering, Shanghai University of Engineering Science, China. He received Ph.D. degree from Yamagata University, Japan. His main research interests include mechanism of metal cutting chatter and its active control.

Cong Mao, a professor at College of Automotive and Mechanical Engineering, Changsha University of Science and Technology, China. He received Ph.D. degree from Hunan University, China. His main research interests include cutting and grinding theory and equipment.
Hao Nan Li, a professor at School of Aerospace, University of Nottingham Ningbo China. He received Ph.D. degree from Northeastern University, China. His main research interests include machining of aerospace materials.

Gupta Munish Kumar, a postdoctoral fellow at Key Lab High Efficiency and Clean Mech. Manufacture, Shandong University, China. His main research interests include hybrid cryo-lubrication assisted turning.

Zafar Said, an assistant professor at College of Engineering, University of Sharjah, United Arab Emirates. His main research interests include sustainable and renewable energy engineering.

Sujan Debnath, a professor at Mechanical Engineering Department, Curtin University, Malaysia. He obtained his Ph.D. Degree from the University of Science Malaysia in 2006 majoring applied mechanics with specific research focuses on interfacial thermal mismatch stress analysis in layered structure.

Muhammad Jamil, a postdoctoral fellow at College of Mechanical and Electrical Engineering, Nanjing University of Aeronautics and Astronautics, China. His main research interests include sustainable cutting.

Hafiz Muhammad Ali, an associate professor at Mechanical Engineering Department, King Fahd University of Petroleum and Minerals, Saudi Arabia. He received Ph.D. degree from University of London, UK. The main research interests is heat transfer.

\section{Funding}

Supported by National Natural Science Foundation of China (Grant Nos. 51975305, 51905289), Major Research Project of Shandong Province of China (Grant Nos. 2019GGX104040, 2019GSF108236), Major Science and Technology Innovation Engineering Projects of Shandong Province of China (Grant No. 2019JZZY020111), the Natural Science Foundation of Shandong Province (Grant Nos. ZR2020KE027 and ZR2020ME158) and Applied Basic Research Youth Project of Qingdao Science and Technology Plan of China (Grant No. 19-6-2-63-cg)

\section{Competing Interests}

The authors declare no competing financial interests.

\section{Author Details}

${ }^{1}$ School of Mechanical and Automotive Engineering, Qingdao University of Technology, Qingdao 266520, China. ${ }^{2}$ College of Mechanical and Electrical Engineering, Nanjing University of Aeronautics and Astronautics, Nanjing 210016, China. ${ }^{3}$ State Key Laboratory Mechanical Transmiss, Chongqing University, Chongqing 400044, China. ${ }^{4}$ Key Laboratory of Special Purpose Equipment and Advanced Processing Technology, Ministry of Education \& Zhejiang Province, Zhejiang University of Technology, Hangzhou 310032, China. ${ }^{5}$ School of Mechanical and Automotive Engineering, Shanghai University of Engineering Science, Shanghai 201620, China. ${ }^{6}$ College of Automotive and Mechanical Engineering, Changsha University of Science and Technology, Changsha 410114, China. ${ }^{7}$ School of Aerospace, University of Nottingham Ningbo China, Ningbo 315100, China. ${ }^{8}$ Key Lab High Efficiency and Clean Mech Manufacture, Shandong University, Jinan 250100, China. ${ }^{9}$ College of Engineering, University of Sharjah, 27272 Sharjah, United Arab Emirates.

${ }^{10}$ Mechanical Engineering Department, Curtin University, 98009 Miri, Malaysia.

${ }^{11}$ Mechanical Engineering Department, King Fahd University of Petroleum and Minerals, Dhahran 31261, Saudi Arabia.

Received: 1 September 2020 Revised: 18 December 2020 Accepted: 11 January 2021

Published online: 10 February 2021

\section{References}

[1] M C Santos, A R Machado, W F Sales, et al. Machining of aluminum alloys: a review. Int. J. Adv. Manuf. Tech., 2016, 86(9-12): 3067-3080.

[2] H Demir, S Gunduz. The effects of aging on machinability of 6061 aluminium alloy. Mater. Design, 2009, 30(5): 1480-1483. 
[3] X-L Hu, X Ai, Y Wan, et al. Flow stress modeling for aeronautical aluminum alloy 7050-T7451 in high-speed cutting. Transactions of Nanjing University of Aeronautics \& Astronautics, 2007, 24(2): 139-144.

[4] E A S Jr, JT Staley. Application of modern aluminium alloys to aircraft. Fundamentals of Aluminium Metallurgy, 2011: 747-783.

[5] K Zheng, D J Politis, L Wang, et al. A review on forming techniques for manufacturing lightweight complex-shaped aluminium panel components. International Journal of Lightweight Materials \& Manufacture, 2018: S258884041830012X.

[6] R S Anand, K Patra. Modeling and simulation of mechanical micromachining-A review. Machining Science \& Technology, 2014, 18(3): 323-347.

[7] T Dursun, C Soutis. Recent developments in advanced aircraft aluminium alloys. Mater. Design, 2014, 56(56): 862-871.

[8] ZT Tang, Z Q Liu, Y Z Pan, et al. The influence of tool flank wear on residual stresses induced by milling aluminum alloy. J. Mater. Process Tech., 2009, 209(9): 4502-4508.

[9] J Joel, M Anthony Xavior. Aluminium alloy composites and its machinability studies: A review. Materials Today: Proceedings, 2018, 5(5, Part 2): 13556-13562.

[10] Z J Duan, Q G Yin, C H Li, et al. Milling force and surface morphology of 45 steel under different $\mathrm{Al} 2 \mathrm{O} 3$ nanofluid concentrations. Int. J. Adv. Manuf. Tech., 2020, 107(3-4): 1277-1296.

[11] X F Bai, F M Zhou, C H Li, et al. Physicochemical properties of degradable vegetable-based oils on minimum quantity lubrication milling. Int. J. Adv. Manuf. Tech., 2020, 106(9-10): 4143-4155.

[12] L Dong, C H Li, X F Bai, et al. Analysis of the cooling performance of Ti-6Al-4V in minimum quantity lubricant milling with different nanoparticles. Int. J. Adv. Manuf. Tech., 2019, 103(5-8): 2197-2206.

[13] M Albertí, J Ciurana, C A Rodriguez. Experimental analysis of dimensional error vs. cycle time in high-speed milling of aluminium alloy. International Journal of Machine Tools \& Manufacture, 2007, 47(2): 236-246.

[14] X F Bai, C H Li, L Dong, et al. Experimental evaluation of the lubrication performances of different nanofluids for minimum quantity lubrication (MQL) in milling Ti-6Al-4V. Int. J. Adv. Manuf. Tech., 2019, 101(9-12): 2621-2632.

[15] Q A Yin, C H Li, L Dong, et al. Effects of the physicochemical properties of different nanoparticles on lubrication performance and experimental evaluation in the NMQL milling of Ti-6Al-4V. Int. J. Adv. Manuf. Tech., 2018, 99(9-12): 3091-3109.

[16] Q A Yin, C H Li, Y B Zhang, et al. Spectral analysis and power spectral density evaluation in Al2O3 nanofluid minimum quantity lubrication milling of 45 steel. Int. J. Adv. Manuf. Tech., 2018, 97(1-4): 129-145.

[17] R A Mali, R Aiswaresh, TV K Gupta. The influence of tool-path strategies and cutting parameters on cutting forces, tool wear and surface quality in finish milling of Aluminium 7075 curved surface. Int. J. Adv. Manuf. Tech., 2020, 108(1-2): 589-601.

[18] M Chen, L Gongyu, J Dang, et al. Effects of tool helix angles on machined surface morphology in tilt side milling of cantilever thinwalled plates. Procedia CIRP, 2018, 71: 93-98.

[19] W Jomaa, V Songmene, P Bocher. Surface finish and residual stresses induced by orthogonal dry machining of AA7075-T651. Materials, 2014, 7(3): 1603-1624

[20] T Ranjan Soren, R Kumar, I Panigrahi, et al. Machinability behavior of aluminium alloys: A brief study. Materials Today: Proceedings, 2019, 18: 5069-5075.

[21] N D Huang, E Krebs, J Baumann, et al. Experimental investigation on influence of engagement angle and tool geometry on plunge milling. Int. J. Adv. Manuf. Tech., 2020, 108(5-6): 1973-1981.

[22] S S Qu, Y D Gong, Y Y Yang, et al. Investigating minimum quantity lubrication in unidirectional $\mathrm{Cf} / \mathrm{SiC}$ composite grinding. Ceramics International, 2020, 46(3): 3582-3591.

[23] K Saptaji, S Subbiah, J S Dhupia. Effect of side edge angle and effective rake angle on top burrs in micro-milling. Precis. Eng., 2012, 36(3): 444-450.

[24] F Jiang, T Zhang, L Yan. Analytical model of milling forces based on time-variant sculptured shear surface. Int. J. Mech. Sci., 2016, 115: 190-201.

[25] M Yang, C H Li, Y B Zhang, et al. Predictive model for minimum chip thickness and size effect in single diamond grain grinding of zirconia ceramics under different lubricating conditions. Ceram. Int., 2019 , 45(12): 14908-14920.

[26] M Yang, C H Li, Y B Zhang, et al. Effect of friction coefficient on chip thickness models in ductile-regime grinding of zirconia ceramics. Int. J. Adv. Manuf. Tech., 2019, 102(5-8): 2617-2632.

[27] H N Li, J P Wang, C Q Wu, et al. Damage behaviors of unidirectional CFRP in orthogonal cutting: A comparison between single- and multiple-pass strategies. Compos Part B-Eng, 2020, 185: 107774. https:// doi.org/10.1016/j.compositesb.2020.107774.

[28] T Gao, X P Zhang, C H Li, et al. Surface morphology evaluation of multi-angle 2D ultrasonic vibration integrated with nanofluid minimum quantity lubrication grinding. J. Manuf. Process, 2020, 51: 44-61.

[29] T Gao, C H Li, Y B Zhang, et al. Dispersing mechanism and tribological performance of vegetable oil-based CNT nanofluids with different surfactants. Tribol. Int., 2019, 131: 51-63.

[30] WTWu, C H Li, M Yang, et al. Specific energy and G ratio of grinding cemented carbide under different cooling and lubrication conditions. Int. J. Adv. Manuf. Tech., 2019, 105(1-4): 67-82.

[31] X Cui, C H Li, Y B Zhang, et al. Tribological properties under the grinding wheel and workpiece interface by using graphene nanofluid lubricant. Int. J. Adv. Manuf. Tech., 2019, 104(9-12): 3943-3958.

[32] X W Zhang, T B Yu, W S Wang. Prediction of cutting forces and instantaneous tool deflection in micro end milling by considering tool run-out. Int. J. Mech. Sci., 2018, 136: 124-133.

[33] L TWang, Y L Ke, Z G Huang. Experimental study on milling-force model in aviation aluminum 7050-T7451. China Mechanical Engineering, 2003, 14(19): 1684-1686. (in Chinese)

[34] S S Qu, Y D Gong, Y Y Yang, et al. An investigation of carbon nanofluid minimum quantity lubrication for grinding unidirectional carbon fibrereinforced ceramic matrix composites. Journal of Cleaner Production, 2020, 249: 119353.

[35] Z Q Liu, Q D Wang, A M Tang, et al. Modeling and numerical simulation of instantaneous cutting forces for corner radius end mills. Journal of Basic Science and Engineering, 2012, 20(6): 1022-1031.

[36] K-H Fuh, R-M Hwang. A predicted milling force model for high-speed end milling operation. International Journal of Machine Tools \& Manufacture, 1997, 37(7): 969-979.

[37] RW Yuan, M Chen, Z H Qu, et al. Milling force prediction and analysis using statistics method. Journal of Shanghai Jiaotong University, 2001, 35(7): 1040-1044.

[38] Z D Shao, J Sun, X J Jia, et al. Study on milling force of aluminium alloy with carbide end milling cutter. Modular Machine Tool \& Automatic Manufacturing Technique, 2007, (8): 71-73.

[39] M Asad, T Mabrouki, J F Rigal. Finite-element-based hybrid dynamic cutting model for aluminium alloy milling. P. I. Mech. Eng. B-J. Eng., 2010, 224(B1): 1-13.

[40] Y-C Yen, J Söhner, B Lilly, et al. Estimation of tool wear in orthogonal cutting using the finite element analysis. J. Mater. Process Tech., 2004, 146(1): 82-91.

[41] C Maranhao, J P Davim, M J Jackson, et al. FEM machining analysis: influence of rake angle in cutting of aluminium alloys using polycrystalline diamond cutting tools. Int. J. Mater. Prod. Tec., 2010, 37(1-2): 199-213.

[42] S S Qu, Y D Gong, Y Y Yang et al. Mechanical model and removal mechanism of unidirectional carbon fibre-reinforced ceramic composites. International Journal of Mechanical Sciences, 2020, 173: 105465.

[43] Z-C Lin, W-L Lai, HY Lin, et al. The study of ultra-precision machining and residual stress for NiP alloy with different cutting speeds and depth of cut. J. Mater. Process Tech., 2000, 97(1): 200-210.

[44] R J Saffar, M R Razfar, O Zarei, et al. Simulation of three-dimension cutting force and tool deflection in the end milling operation based on finite element method. Simul. Model Pract. Th., 2008, 16(10): 1677-1688.

[45] O Gonzalo, H Jauregi, L G Uriarte, et al. Prediction of specific force coefficients from a FEM cutting model. Int. J. Adv. Manuf. Tech., 2009, 43(3-4): 348-356.

[46] F Abrari, M A Elbestawi. Closed form formulation of cutting forces for ball and flat end mills. International Journal of Machine Tools and Manufacture, 1997, 37(1): 17-27.

[47] S Engin, Y Altintas. Mechanics analysis and predictive force models for the single-diamond grain grinding of carbon fiber reinforced polymers 
using CNT nano-lubricant. Journal of Materials Processing Technology, 2021: 290. https://doi.org/10.1016/j.jmatprotec.2020.116976.

[48] B P Mann, BT Edes, S J Easley, et al. Chatter vibration and surface location error prediction for helical end mills. International Journal of Machine Tools \& Manufacture, 2008, 48(3-4): 350-361.

[49] A Bhattacharyya, J K Schueller, B P Mann, et al. A closed form mechanistic cutting force model for helical peripheral milling of ductile metallic alloys. International Journal of Machine Tools \& Manufacture, 2010, 50(6): 538-551.

[50] M C Yoon, Y G Kim. Surface morphology assessment of CFRP transverse grinding using CNT nanofluid minimum quantity lubrication. Journal of Cleaner Production, 2020: 277, 123328. https://doi.org/10.1016/j.jclep ro.2020.123328.

[51] O B Adetoro, P H Wen. Prediction of mechanistic cutting force coefficients using ALE formulation. Int. J. Adv. Manuf. Tech., 2010, 46(1-4): 79-90.

[52] Q Y Cao, D Y Xue, J Zhao, et al. A cutting force model considering influence of radius of curvature for sculptured surface machining. Int. J. Adv. Manuf. Tech., 2011, 54(5-8): 821-835.

[53] E Budak. Analytical models for high performance milling. Part l: Cutting forces, structural deformations and tolerance integrity. International Journal of Machine Tools and Manufacture, 2006, 46(12): 1478-1488.

[54] Y S Dambatta, M Sayuti, A A D Sarhan, et al. Prediction of specific grinding forces and surface roughness in machining of AL6061-T6 alloy using ANFIS technique. Ind. Lubr. Tribol., 2019, 71(2): 309-317.

[55] I A Daniyan, I Thabadira, K Mpofu, et al. Process design and optimization for the milling operation of aluminum alloy (AA6063 T6). Materials Today: Proceedings, 2020.

[56] YWan, Z Liu, X Ai, et al. Tool wear patterns and mechanisms of solid cemented carbide in high-speed milling of aluminum alloy. Transactions of Nanjing University of Aeronautics and Astronautics, 2007, 24(2): 125-128.

[57] M Binder, F Klocke, B Doebbeler. An advanced numerical approach on tool wear simulation for tool and process design in metal cutting. Simul. Model Pract. Th., 2017, 70: 65-82.

[58] W Lai, B Greenway, T Faddis. Flute engagement in peripheral milling. J. Mater. Process Tech., 2001, 117(1): 1-8.

[59] I Okokpujie, O Ikumapayi, U Okonkwo, et al. Experimental and mathematical modeling for prediction of tool wear on the machining of aluminium 6061 alloy by high speed steel tools. Open Engineering, 2018, 7: 461-469.

[60] K Orra, S K Choudhury. Mechanistic modelling for predicting cutting forces in machining considering effect of tool nose radius on chip formation and tool wear land. Int. J. Mech. Sci., 2018, 142: 255-268.

[61] S Shankar, T Mohanraj, R Rajasekar. Prediction of cutting tool wear during milling process using artificial intelligence techniques. Int. J. Comput. Integ. M., 2019, 32(2): 174-182.

[62] Z Duan, C Li, Y Zhang, et al. Milling surface roughness for 7050 aluminum alloy cavity influenced by nozzle position of nanofluid minimum quantity lubrication. Chinese Journal of Aeronautics, 2020.

[63] S Amaitik, TT Tasgin, S Kilic. Tool-life modelling of carbide and ceramic cutting tools using multi-linear regression analysis. Proceedings of the Institution of Mechanical Engineers, Part B, Journal of Engineering Manufacture, 2006, 220: 129-136.

[64] S Berczyński, P Gutowski. Identi cation of the dynamic models of machine tool supporting systems. Part I: An algorithm of the method. Journal of Vibration and Control, 2006, 12: 257-277.

[65] YYu, LX Huang, D D Wang. Cutter force experiment and chips analysis of end milling cutter in milling aluminium alloy. Tool Engineering, 2015, (2): 20-23.

[66] Y Z Pan, X Ai, ZTTang, et al. Optimization of tool geometry and cutting parameters based on a predictive model of cutting force. China Mechanical Engineering, 2008, 19(4):428-431. (in Chinese)

[67] KY Tang, L H Zhou, L Song. Research on milling of 7050-T7451 aeronautical aluminum alloy by orthogonal experiments. Cemented Carbide, 2011, 28(3): 172-176.

[68] H Guo. Study on mechanism and prediction analysis of machining distortion for aero-multi-frame monolithic structure parts. Nanjing: Nanjing University of Aeronautics and Astronautics, 2005. https://doi.org/10.7666/d. d016058.
[69] X L Wang, Y Zhang. Experiment and modeling of aluminum alloy milling based on orthogonal test method. Machinery, 2017, 55(8): 8-10. https://doi.org/10.3969/j.issn.1000-4998.2017.08.003.

[70] J J Sun, X Kong, J S Yuan, et al. Experimental study of ball-end milling force of 6061 aluminum alloy. Tool Engineering, 2011, 45(1): 22-25.

[71] X L Jin, Y Altintas. Slip-line field model of micro-cutting process with round tool edge effect. J. Mater. Process Tech., 2011, 211(3): 339-355.

[72] X B Jing, RY Lv, Y Chen, et al. Modelling and experimental analysis of the effects of run out, minimum chip thickness and elastic recovery on the cutting force in micro-end-milling. Int. J. Mech. Sci., 2020, 176: 105540.

[73] FX Zhang. Modeling and analysis of micro milling forces. Harbin: Harbin Institute of Technology, 2007. https://doi.org/10.7666/d.D273634.

[74] W-Y Bao. Tool cutting force modeling and wear estimation of microend-milling operations. ProQuest ETD Collection for FIU, 1999.

[75] Z Q Zhang. Milling force modeling of alloy 2219 arc plates and its influence on residual stress. Jinan: Shandong University, 2019.

[76] O Pantalé, J L Bacaria, O Dalverny, et al. 2D and 3D numerical models of metal cutting with damage effects. Computer Methods in Applied Mechanics and Engineering, 2004, 193(39): 4383-4399.

[77] F Hu, D Li. Modelling and simulation of milling forces using an arbitrary Lagrangian-Eulerian finite element method and support vector regression. Journal of Optimization Theory \& Applications, 2012, 153(2): 461-484.

[78] G Yücesan, Y Altintaş. Improved modelling of cutting force coefficients in peripheral milling. International Journal of Machine Tools and Manufacture, 1994, 34(4): 473-487.

[79] B Martin. Finite element simulation of high-speed cutting. Acta Aeronautica Et Astronautica Sinica, 2006, 27(3): 531-535.

[80] J Mackerle. Finite-element analysis and simulation of machining: a bibliography (1976-1996). J. Mater. Process Tech., 1999, 86(1): 17-44.

[81] J Mackerle. Finite element analysis and simulation of adhesive bonding, soldering and brazing an addendum: a bibliography (1996 2002). Modelling and Simulation in Materials Science and Engineering, 2002, 10(6): 637-671.

[82] T Özel, T Altan. Process simulation using finite element method — prediction of cutting forces, tool stresses and temperatures in high-speed flat end milling. International Journal of Machine Tools and Manufacture, 2000, 40(5): 713-738.

[83] HY Dong, Y L Ke. Simulation of 3D chip shaping of aluminum alloy 7075 in milling processes. Transactions of Nonferrous Metals Society of China (English Edition), 2005, 15: 1315-1321.

[84] X Huang, J Xu, M Chen, et al. Finite element modeling of high-speed milling 7050-T7451 alloys. Procedia Manufacturing, 2020, 43: 471-478.

[85] X Man, D Ren, S Usui, et al. Validation of finite element cutting force prediction for end milling. Procedia CIRP, 2012, 1:663-668.

[86] TH Pham, T B Mac, V C Tong, et al. A study on the cutting force and chip shrinkage coefficient in high-speed milling of A6061 aluminum alloy. Int. J. Adv. Manuf. Tech., 2018, 98(1-4): 177-188.

[87] Y Gao, J H Ko, H Lee. 3D Eulerian finite element modelling of end milling. Procedia CIRP, 2018, 77: 159-162.

[88] A Mebrahitom, W Choon, A Azhari. Side milling machining simulation using finite element analysis: Prediction of cutting forces. Materials Today: Proceedings, 2017, 4(4, Part D): 5215-5221.

[89] ZY Zhang, G D Chen, TWang. Study on the milling force and milling temperature for end milling of aluminum alloy 7055. Machinery Design \& Manufacture, 2014, (6): 75-78.

[90] J Yu, G W Yang. FEM simulation for milling force of aeronautical thinwalled workpiece. Machine Tool \& Hydraulics, 2011, 39(21): 136-137.

[91] HX Ji, M J Ge, J Yu, et al. FEA modeling and experimental analysis of mimng of 7050-T7451 aluminum alloy thin-walled part. Modern Machinery, 2018, (6): 15-18.

[92] M Wan, W H Zhang. Efficient algorithms for calculations of static form errors in peripheral milling. J. Mater. Process Tech. 2006, 171(1): 156-165.

[93] Y Liu, H N Bie. Simulation and prediction of micro-milling force for AL6061. Tool Engineering, 2016, 50(12): 29-35.

[94] Q Sun, X Cheng, Y Liu, et al. Modeling and simulation for micromilling mechanisms. Procedia Engineering, 2017, 174: 760-766.

[95] B M Imani, M Pour, A Ghoddosian, et al. Improved dynamic simulation of end-milling process using time series analysis. Sci. Iran, 2012, 19(2): 294-302. 
[96] A Davoudinejad, D Li, Y Zhang, et al. Optimization of corner micro end milling by finite element modelling for machining thin features. Procedia CIRP, 2019, 82: 362-367.

[97] M Cai, Y D Gong, N Yu, et al. Simulation and experimental study on the milling force of aluminum alloy 6061 in micro-milling. Journal of Northeastern University(Natural Science), 2016, 39(1): 76-81.

[98] CXYue, C B Cai, C Huang, et al. Recent advances in finite element simulation of machining processes. Journal of System Simulation, 2016 28(4): 815-825.

[99] O D YIImaz, S N B Oliaei. Effect of constitutive material model on the finite element simulation of shear localization onset. Simul. Model Pract. Th., 2020: 102105.

[100] Z Q Liu, K G Zhang. Sensitivity analysis of johnson-cook material constants on adiabatic shear. Chinese Journal of Aeronautics, 2011, 32(11): 2140-2146.

[101] Z Q Liu, J H Wu, Z Y Shi, et al. State-of-the-art of constitutive equations in metal cutting operations. Tool Engineering, 2008, 42(3): 3-9.

[102] Y Z Hua, LW Guan, X J Liu, et al. Research and revise on constitutive equation of 7050-T7451 aluminum alloy in high strain rate and high temperature condition. Journal of Materials Engineering, 2012, (12): 7-13.

[103] Y B Guo. An integral method to determine the mechanical behavior of materials in metal cutting. J. Mater. Process Tech., 2003, 142(1): 72-81.

[104] T Zel, Y Karpat. Identification of constitutive material model parameters for high-strain rate metal cutting conditions using evolutionary computational algorithms. Advanced Manufacturing Processes, 2007, 22(5): 659-667.

[105] M Shatla, C Kerk, T Altan. Process modeling in machining. Part I: determination of flow stress data. International Journal of Machine Tools and Manufacture, 2001, 41(10): 1511-1534.

[106] J Limido, C Espinosa, M Salaün, et al. SPH method applied to high speed cutting modelling. Int. J. Mech. Sci., 2007, 49(7): 898-908.

[107] K Liu, S N Melkote. Finite element analysis of the influence of tool edge radius on size effect in orthogonal micro-cutting process. Int. J. Mech. Sci, 2007, 49(5): 650-660.

[108] A Adibi-Sedeh, V Madhavan, B Bahr. Extension of Oxley's analysis of machining to use different material models. Journal of Manufacturing Science and Engineering-Transactions of the ASME, 2003, 125(4): 656-666.

[109] K Senthil, M A lqbal, P S Chandel, et al. Study of the constitutive behavior of 7075-T651 aluminum alloy. International Journal of Impact Engineering, 2017, 108: 171-190.

[110] N N Zorev. Inter-relationship between shear processes occurring along tool face and shear plane in metal cutting. Proceedings of the International Production Engineering Research Conference, 1963: 42-49.

[111] M Calamaz, D Coupard, F Girot. A new material model for 2D numerical simulation of serrated chip formation when machining titanium alloy Ti-6Al-4V. International Journal of Machine Tools \& Manufacture, 2008 48(3-4): 275-288.

[112] T Shirakashi, E Usui. Simulation analysis of orthogonal metal cutting process. Journal of the Japan Society of Precision Engineering, 1976, 42(496): 340-345.

[113] K Iwata, K Osakada, Y Terasaka. Process modelling of orthogonal cutting by the rigid plastic finite element method. Journal of Engineering Materials and Technology, Transactions of the ASME, 1984, 106(2): 132-138.

[114] M Vaz Jr. On the numerical simulation of machining processes. Journal of the Brazilian Society of Mechanical Sciences, 2000, 22(2): 179-188.

[115] X Yang, C R Liu. A new stress-based model of friction behavior in machining and its significant impact on residual stresses computed by finite element method. Int. J. Mech. Sci., 2002, 44(4): 703-723.

[116] W-S Yun, D-W Cho. Accurate 3-D cutting force prediction using cutting condition independent coefficients in end milling. International Journal of Machine Tools and Manufacture, 2001, 41(4): 463-478.

[117] K A Desai, P K Agarwal, PV M Rao. Process geometry modeling with cutter runout for milling of curved surfaces. International Journal of Machine Tools and Manufacture, 2009, 49(12): 1015-1028.

[118] D Montgomery, Y Altintas. Mechanism of cutting force and surface generation in dynamic milling. Journal of Engineering for Industry, 1991, 113(2): 160-168

[119] V Rao, PV M Rao. Effect of workpiece curvature on cutting forces and surface error in peripheral milling. Proceedings of the Institution of Mechanical Engineers Part B-Journal of Engineering Manufacture, 2006, 220: 1399-1407.
[120] P Oxley, M Shaw. Mechanics of machining: An analytical approach to assessing machinability. Journal of Applied Mechanics, 1990, 57(1): 253-253.

[121] F Koenigsberger, A J P Sabberwal. An investigation into the cutting force pulsations during milling operations. International Journal of Machine Tool Design and Research, 1961, 1(1): 15-33.

[122] STangjitsitcharoen, P Thesniyom, S Ratanakuakangwan. Prediction of surface roughness in ball-end milling process by utilizing dynamic cutting force ratio. J. Intell. Manuf., 2017, 28(1): 13-21.

[123] L Zheng, Y S Chiou, S Y Liang. Three dimensional cutting force analysis in end milling. Int. J. Mech. Sci., 1996, 38(3): 259-269.

[124] E Budak, Y Altintas. Modeling and avoidance of static form errors in peripheral milling of plates. International Journal of Machine Tools and Manufacture, 1995, 35(3): 459-476.

[125] W A Kline, R E DeVor, J R Lindberg. The prediction of cutting forces in end milling with application to cornering cuts. International Journal of Machine Tool Design and Research, 1982, 22(1): 7-22.

[126] W S Yun, D W Cho. An improved method for the determination of 3D cutting force coefficients and runout parameters in end milling. The International Journal of Advanced Manufacturing Technology, 2000, 16(12): 851-858

[127] E Abele, S Dietz, A Schiffler. Analysis of cutting force during milling with regards to the dependency on the penetration angle. Production Engineering, 2009, 3(4): 483.

[128] L Pang, A Hosseini, H M Hussein, et al. Application of a new thick zone model to the cutting mechanics during end-milling. Int. J. Mech. Sci., 2015, 96: 91-100

[129] F A Niaki, A Pleta, L Mears. Trochoidal milling: investigation of a new approach on uncut chip thickness modeling and cutting force simulation in an alternative path planning strategy. Int. J. Adv. Manuf. Tech., 2018, 97(1-4): 641-656.

[130] K Li, K Zhu, T Mei. A generic instantaneous undeformed chip thickness model for the cutting force modeling in micromilling. International Journal of Machine Tools and Manufacture, 2016, 105: 23-31.

[131] WY Bao, I N Tansel. Modeling micro-end-milling operations. Part I: analytical cutting force model. International Journal of Machine Tools and Manufacture, 2000, 40(15): 2155-2173.

[132] P Sahoo, K Patra. Mechanistic modeling of cutting forces in microend-milling considering tool run out, minimum chip thickness and tooth overlapping effects. Machining Science \& Technology, 2019, 23(3): 407-430.

[133] A S Wojciechowski, M Matuszak, B Powalka, et al. Prediction of cutting forces during micro end milling considering chip thickness accumulation. International Journal of Machine Tools \& Manufacture, 2019. https:// doi.org/10.1016/j.ijmachtools.2019.103466.

[134] X Liu, R DeVor, F Asme, et al. Investigation of the Dynamics of Microend Milling —Part I: Model Development. Journal of Manufacturing Science and Engineering-Transactions of the ASME, 2006, 128(4): 893-900.

[135] P Rodriguez, J E Labarga. A new model for the prediction of cutting forces in micro-end-milling operations. J. Mater. Process Tech., 2013, 213(2): 261-268

[136] L M Kumanchik, T L Schmitz. Improved analytical chip thickness model for milling. Precision Engineering, 2007, 31(3): 317-324

[137] XW Zhang, K F Ehmann, T B Yu, et al. Cutting forces in micro-endmilling processes. International Journal of Machine Tools \& Manufacture, 2016, 107: 21-40.

[138] Y H Kang, C M Zheng. Mathematical modelling of chip thickness in micro-end-milling: A Fourier modelling. Appl. Math. Model, 2013, 37(6): 4208-4223.

[139] M H M Dib, J G Duduch, R G Jasinevicius. Minimum chip thickness determination by means of cutting force signal in micro endmilling. Precis. Eng., 2018, 51: 244-262.

[140] M Wan, D-Y Wen, Y-C Ma, et al. On material separation and cutting force prediction in micro milling through involving the effect of dead metal zone. International Journal of Machine Tools and Manufacture, 2019, 146: 103452.

[141] M Wan, W H Zhang, G Tan, et al. Systematic simulation procedure of peripheral milling process of thin-walled workpiece. J. Mater. Process Tech., 2008, 197(1-3):122-131.

[142] H-Y Feng, C-H Menq. The prediction of cutting forces in the ball-end milling process—I. Model formulation and model building procedure. 
International Journal of Machine Tools and Manufacture, 1994, 34(5): 697-710.

[143] B M Imani, M H Sadeghi, M A Elbestawi. An improved process simulation system for ball-end milling of sculptured surfaces. International Journal of Machine Tools and Manufacture, 1998, 38(9): 1089-1107.

[144] K A Desai, P K Agarwal, PV M Rao. Process geometry modeling with cutter runout for milling of curved surfaces. International Journal of Machine Tools \& Manufacture, 2009, 49(12-13): 1015-1028.

[145] HY Hao, W C Tang, B S Wang. Modeling and analysis of milling force in peripheral milling of curved surface with variable curvature. Manufacturing Technology \& Machine Tool, 2014, (7): 118-122.

[146] J H Ko. 3D ball-end milling force model using instantaneous cutting force coefficients. Journal of Manufacturing Science and EngineeringTransactions of the ASME, 2005, 127(1): 1-12

[147] S B Wang, L Geng, Y F Zhang, et al. Cutting force prediction for five-axis ball-end milling considering cutter vibrations and run-out. Int. J. Mech Sci., 2015, 96: 206-215

[148] S Lotfi, B Rami, B Maher, et al. An approach to modeling the chip thick ness and cutter workpiece engagement region in 3 and 5 axis ball end milling. J. Manuf. Process, 2018, 34: 7-17.

[149] M Martelloti. An analysis of the milling process. Trans. ASME, 1941, 63: 677-700.

[150] J Gradišek, M Kalveram, K Weinert. Mechanistic identification of specific force coefficients for a general end mill. International Journal of Machine Tools and Manufacture, 2004, 44(4): 401-414.

[151] Y Altintas, P Lee. Mechanics and dynamics of ball end milling. Journal of Manufacturing Science and Engineering-Transactions of the ASME, 1998, 120(4): 684-692

[152] S Jayaram, S G Kapoor, R E DeVor. Estimation of the specific cutting pressures for mechanistic cutting force models. International Journal of Machine Tools and Manufacture, 2001, 41(2): 265-281.

[153] M Wan, W H Zhang, G H Qin, et al. Efficient calibration of instantaneous cutting force coefficients and runout parameters for general end mills. International Journal of Machine Tools and Manufacture, 2007, 47(11): 1767-1776.

[154] M Wan, W H Zhang. Systematic study on cutting force modelling methods for peripheral milling. International Journal of Machine Tools \& Manufacture, 2009, 49(5):424-432.

[155] J J Junz Wang, C M Zheng. An analytical force model with shearing and ploughing mechanisms for end milling. International Journal of Machine Tools and Manufacture, 2002, 42(7):761-771.

[156] K Shirase, Y Altintaş. Cutting force and dimensional surface error generation in peripheral milling with variable pitch helical end mills. International Journal of Machine Tools and Manufacture, 1996, 36(5): 567-584.

[157] D Merdol, Y Altintas. Mechanics and dynamics of serrated cylindrical and tapered end mills. Journal of Manufacturing Science and Engineering-Transactions of the ASME, 2004, 126(2): 317-326.

[158] S-M Wang, C-H Chiou, Y-M Cheng. An improved dynamic cutting force model for end-milling process. J. Mater. Process Tech., 2004, 148(3): 317-327.

[159] K A Desai, PV M Rao. Effect of direction of parameterization on cutting forces and surface error in machining curved geometries. International Journal of Machine Tools \& Manufacture, 2008, 48(2): 249-259.

[160] I Zaghbani, V Songmene. A force-temperature model including a constitutive law for dry high speed milling of aluminium alloys. J. Mater. Process Tech., 2009, 209(5): 2532-2544.

[161] E Riviere-Lorphevre, E Filippi. Mechanistic cutting force model parameters evaluation in milling taking cutter radial runout into account. Int J. Adv. Manuf. Tech., 2009, 45(1-2): 8-15.

[162] T Matsumura, S Tamura. Cutting force model in milling with cutter runout. Procedia CIRP, 2017, 58: 566-571.

[163] K Kiran, M C Kayacan. Cutting force modeling and accurate measurement in milling of flexible workpieces. Mech. Syst. Signal. Pr., 2019, 133:106284. https://doi.org/10.1016/j.ymssp.2019.106284.

[164] M H Wang, L Gao, Y H Zheng. An examination of the fundamental mechanics of cutting force coefficients. International Journal of Machine Tools \& Manufacture, 2014, 78: 1-7.

[165] P J Cheng, J TTsay, S C Lin. A study on instantaneous cutting force coefficients in face milling. International Journal of Machine Tools and Manufacture, 1997, 37(10): 1393-1408.
[166] A Azeem, H-Y Feng, L Wang. Simplified and efficient calibration of a mechanistic cutting force model for ball-end milling. International Journal of Machine Tools and Manufacture, 2004, 44(2): 291-298.

[167] E J A Armarego, R C Whitfield. Computer based modelling of popular machining operations for force and power prediction. CIRP Annals, 1985, 34(1): 65-69.

[168] P Lee, Y Altintaş. Prediction of ball-end milling forces from orthogonal cutting data. International Journal of Machine Tools and Manufacture, 1996, 36(9): 1059-1072.

[169] Y Altintas, A Spence, J Tlusty. End milling force algorithms for CAD systems. CIRP Annals, 1991, 40(1): 31-34.

[170] W Endres, R DeVor, S Kapoor. A dual-mechanism approach to the prediction of machining forces, Part 1: Model development. Journal of Engineering for Industry, 1995, 117(4): 526-533.

[171] W Endres, R DeVor, S Kapoor. A dual-mechanism approach to the prediction of machining forces, Part 2: Calibration and validation. Journal of Engineering for Industry, 1995, 117(4): 534-541.

[172] C Zheng, J J Wang. Estimation of in-process cutting constants in ballend milling. Proceedings of the Institution of Mechanical Engineers Part B-Journal of Engineering Manufacture, 2003, 217: 45-56.

[173] E Rivière-Lorphèvre, E Filippi. Mechanistic cutting force model parameters evaluation in milling taking cutter radial runout into account. The International Journal of Advanced Manufacturing Technology, 2009, 45(1): 8.

[174] J H Ko, W-S Yun, D-W Cho, et al. Development of a virtual machining system, part 1: approximation of the size effect for cutting force prediction. International Journal of Machine Tools and Manufacture, 2002, 42(15): 1595-1605

[175] J H Ko, D-W Cho. Determination of cutting-condition-independent coefficients and runout parameters in ball-end milling. The International Journal of Advanced Manufacturing Technology, 2005, 26(11): 1211-1221.

[176] Y G Kang, Z Q Wang, J J Wu, et al. Study of the classification of cutting forces and the build of the accurate milling force model in end milling. Chinese Journal of Aeronautics, 2007, 28(2): 230-238.

[177] L Yin, Q Liu. Study on the identification of the milling force parameter model based on partial least square regression and application. Mechanical Science and Technology, 2005, 24(3): 269-272.

[178] H J Qi. Modeling methodology of milling deflection and flexible milling force for tooth profile of low-rigidity cycloid gear in high speed milling. Tianjin:Tianjin University, 2009. https://doi.org/10.7666/d.y1677933.

[179] G Campatelli, A Scippa. Prediction of milling cutting force coefficients for aluminum 6082-T4. Procedia CIRP, 2012, 1: 563-568.

[180] X L Liu, H N Gao, C X Yue, et al. Investigation of the milling stability based on modified variable cutting force coefficients. Int. J. Adv. Manuf. Tech., 2018, 96(9-12): 2991-3002.

[181] G Yu, L P Wang, J Wu. Prediction of chatter considering the effect of axial cutting depth on cutting force coefficients in end milling. Int. J. Adv. Manuf. Tech., 2018, 96(9-12): 3345-3354.

[182] S Liu, S Jin. Predicting milling force variation in time and space domain for multi-toothed face milling. Int. J. Adv. Manuf. Tech., 2020, 108(7-8): 2269-2283.

[183] Y C Kao, NT Nguyen, M S Chen, et al. A prediction method of cutting force coefficients with helix angle of flat-end cutter and its application in a virtual three-axis milling simulation system. Int. J. Adv. Manuf. Tech., 2015, 77(9-12): 1793-1809.

[184] K A M Adem, R Fales, A S El-Gizawy. Identification of cutting force coefficients for the linear and nonlinear force models in end milling process using average forces and optimization technique methods. Int. J. Adv. Manuf. Tech., 2015, 79(9-12): 1671-1687.

[185] MY Tsai, SY Chang, J P Hung, et al. Investigation of milling cutting forces and cutting coefficient for aluminum 6060-T6. Comput. Electr. Eng., 2016, 51: 320-330.

[186] E Ozturk, O Ozkirimli, T Gibbons, et al. Prediction of effect of helix angle on cutting force coefficients for design of new tools. CIRP Annals, 2016, 65(1): 125-128.

[187] B Tukora, T Szalay. Real-time determination of cutting force coefficients without cutting geometry restriction. International Journal of Machine Tools \& Manufacture, 2011, 51(12): 871-879.

[188] W J Bai. Study on deformation prediction theory and methods of the aerospace thin-walled components during precision milling process. Hangzhou: Zhejiang University, 2009. 
[189] L Arnaud, O Gonzalo, S Seguy, et al. Simulation of low rigidity part machining applied to thin-walled structures. The International Journal of Advanced Manufacturing Technology, 2011, 54(5): 479-488.

[190] Q Liu, Z Q Li. Simulation and optimization of CNC milling process-Modeling, algorithms and applications. Beijing: Aviation industry press, 2011.

[191] M Wan, W H Zhang, G H Qin, et al. Consistency study on three cutting force modelling methods for peripheral milling. P. I. Mech. Eng. B-J. Eng 2008, 222(6): 665-676.

[192] Y C Shin, A J Waters. A new procedure to determine instantaneous cutting force coefficients for machining force prediction. International Journal of Machine Tools and Manufacture, 1997, 37(9): 1337-1351.

[193] M Wan, W-H Zhang. Systematic study on cutting force modelling methods for peripheral milling. International Journal of Machine Tools and Manufacture, 2009, 49(5): 424-432.

[194] F Ning, W Fuji, J Ma. A new modeling method for cutting forces in side milling of aluminum alloy. International Conference on Mechanical Design, Phuket, Thailand, 2014.

[195] J-S Tsai, C-L Liao. Finite-element modeling of static surface errors in the peripheral milling of thin-walled workpieces. J. Mater. Process Tech., 1999, 94(2): 235-246.
[196] GM Kim, B H Kim, CN Chu. Estimation of cutter deflection and form error in ball-end milling processes. International Journal of Machine Tools and Manufacture, 2003, 43(9): 917-924.

[197] A P Xu, YX Qu, DW Zhang, et al. Simulation and experimental inves tigation of the end milling process considering the cutter flexibility. International Journal of Machine Tools and Manufacture, 2003, 43(3): 283-292.

[198] M Dotcheva, H Millward, A Lewis. The evaluation of cutting-force coefficients using surface error measurements. J. Mater. Process Tech., 2008 196(1-3): 42-51.

[199] Z M Hu, Z Q Wang, J J Wu, et al. Study on prediction of milling force in peripheral milling of thin-walled workpiece. Machine Tool \& Hydraulics, 2008, 36(3): 1-4.

[200] E Ozturk, O Ozkirimli, T Gibbons, et al. Prediction of effect of helix angle on cutting force coefficients for design of new tools. CIRP Ann.-Manuf. Techn., 2016, 65(1): 125-128.

[201] D Chen, X Zhang, Y Xie, et al. Precise estimation of cutting force coefficients and cutter runout in milling using differential evolution algorithm. Procedia CIRP, 2018, 77: 283-286.

\section{Submit your manuscript to a SpringerOpen ${ }^{\circ}$ journal and benefit from:}

- Convenient online submission

- Rigorous peer review

- Open access: articles freely available online

- High visibility within the field

- Retaining the copyright to your article

Submit your next manuscript at springeropen.com 